\title{
POLICE INTERVIEWS WITH VICTIMS AND SUSPECTS OF VIOLENT AND SEXUAL CRIMES;
}

Interviewees' experiences and interview outcomes

\author{
Ulf Holmberg
}

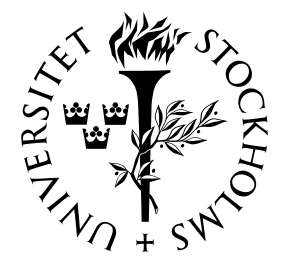

DEPARTMENT OF PSYCHOLOGY

STOCKHOLM UNIVERSITY

2004 
(C) Ulf Holmberg, 2004

ISBN 91-7265-815-0

Akademitryck AB, Edsbruk 2004 
Doctoral Dissertation 2004

Department of Psychology

Stockholm University

S 10691 Stockholm

Sweden

\begin{abstract}
The police interview is one of the most important investigative tools that law enforcement has close at hand, and police interview methods have changed during the twentieth century. A good police interview is conducted in the frame of the law, is governed by the interview goal, and is influenced by facilitating factors that may affect the elicited report. The present doctoral dissertation focuses on police interviews in cases of very serious crimes of violence and sexual offences. Results reveal crime victims' and perpetrators' experiences of being interviewed and police officers' attitudes towards conducting interviews related to traumatizing crimes. Study 1 revealed that when police officers interviewed murderers and sexual offenders, the interviewees perceived attitudes characterized by either dominance or humanity. Police interviews marked by dominance and suspects' responses of anxiety were mainly associated with a higher proportion of denials, whereas an approach marked by humanity, and responses of being respected were significantly associated with admissions. In line with Study 1, the victims of rape and aggravated assault in Study 2 also revealed the experience of two police interview styles, where an interviewing style marked by dominance and responses of anxiety was significantly associated with crime victims' omissions of information. Moreover, a humanitarian interviewing style, and crime victims' feelings of being respected and cooperative, was significantly related to crime victims providing all information from painful events. Special squad police officers' attitudes towards interviewing crime victims, in Study 3, also showed a humanitarian approach and two dominant approaches, one affective and the other refusing. The attitude towards interviewing suspects of crimes in focus revealed humanitarian and dominant interviewing attitudes, and an approach marked by kindness. The present thesis shows that, during their entire career, an overwhelming majority of the special squad police officers have experienced stressful events during patrol as well as investigative duty. Results show that symptoms from stressful event exposures and coping mechanisms are associated with negative attitudes towards interviewing suspects and supportive attitudes towards crime victim interviews. Thus, experiences from stressful exposures may automatically activate egodefensive functions that automatically generate dominant attitudes. Moreover, it is important to offer police officers who have been exposed to stressful events the opportunity to work through their experiences, for example, through debriefing procedures. After debriefings, police officers are better prepared to meet crime victims and suspects and, through conscious closed-loop processes, to conduct police interviews without awaking ego-defensive functions.
\end{abstract}

Keywords: Police interview, police officers, crime victims, suspects, stress, attitude function 

In memory of my father and dedicated to my daughters. 


\section{Acknowledgements}

While writing the last words of this thesis, I have cause to look back on my experience as a police investigator of violent and sexual crimes. Interviews with crime victims and suspects awoke questions of how to make it easier for these people to tell about their very traumatic memories. Those questions trigged my studies in psychology and I am very grateful to the crime victims, the suspects, and the police officers who participated in this research. I am pleased because without their participation, there would have been no thesis.

Next, I wish to express my sincere gratitude to my supervisor, Professor Sven-Åke Christianson, who has become a friend of mine. He introduced me to the scientific field of forensic psychology. His clarity and his talent for seeing the essentials in this forensic research have functioned as a guiding star throughout my work. Along with that, I want to thank him for having had faith in my ability to do this research, for his inspiring encouragement, and his deep interest in my work.

I am also deeply grateful to Professor Henry Montgomery for thoroughly reviewing this manuscript and for inspiring and expanding discussions during examinations in my $\mathrm{PhD}$ program. I wish to express my gratitude to Associate Professor Pär Anders Granhag, who also has thoroughly reviewed this manuscript.

For inspiring encouragements, valuable comments and generous acts, I wish to express my gratitude to Professor David Carson, University of Portsmouth; Assistant Chief Commissioner of the County Police Department in Skåne, Kjell Arne Eliasson; Professor Ronald Fisher, Florida International University; Senior Lecture, Dr. Elia Psouni, and Professor Georg Stenberg, Kristianstad University; Professor David Wexler, University of Arizona; Senior Research Fellow, Dr. Tom Willamson, University of Portsmouth; Professor Bruce Winick, University of Miami.

Moreover, I am grateful to past, present and perhaps future friends such as Angela Ahola, Carola Aili, Anna-Christina Blomkvist, Susanna Bylin, Mats Dahl, Elisabeth Engelberg, Måns Holgerson, Malin Irhammar, Ulf Lundberg, Lena Lundin, Ingemar Karlsson, Ben Naji, Lars-Göran Nilsson, Christer Ohlin, Bo Persson, Jean-Christophe Rohner, Camilla Siotis, Hans Tovoté, Alf and Rut Öien at the Department of Behavioural Sciences, Kristianstad University, the Department of Psychology, Stockholm University and elsewhere for their support and our small talks.

Much of the administrative work has been facilitated by the invaluable help of Marie Lindblom, Ann-Marie Pettersson, Gunhild Seebass and Barbro Svensson. Dear ladies, you have my appreciations. My gratitude goes also to Karen Williams for her skilful proofreading of my manuscripts.

Furthermore, my appreciation goes to the Swedish Victim Fund, The Crime Victim Compensation and Support Authority; the Committee for 
Research, Kristianstad University and Swedish Council for Research in Humanities and Social Sciences; the Swedish Association for Sex Education for providing financial support to my research.

Finally, I wish to express warm and very special thanks to my family. My dear wife, Ann-Charlotte, and my lovely daughters, Caroline and Cecilia, have been worried about me because they thought I worked too much. I am very thankful for their concern and patience, and pleased that they have remained at my side - Thank You! 


\section{List of publications}

The present thesis is based on the following studies:

1. Holmberg, U. \& Christianson, S-Å. (2002). Murderers' and Sexual Offenders' Experiences of Police Interviews and Their Inclination to Admit or Deny Crimes. Behavioral Sciences and the Law, 20: $31-45$.

2. Holmberg, U. (In press). Crime Victims' Experiences of Police Interviews and Their Inclination to Provide or Omit Information. International Journal of Police Science and Management.

3. Holmberg, U., Christianson, S-Å. \& Karlsson, I. Stressful Event Exposure is Related to Police Officers' Attitudes towards Interviewing Crime Victims and Suspects.

Two reviewers and one international editor had suggested publication of this manuscript. However, just before the printing of this thesis, the chief editor of the journal rejected it. The manuscript has thereafter been submitted to another journal. 


\section{Table of contents}

THE CHANGING NATURE OF THE POLICE INTERVIEW ................... 1

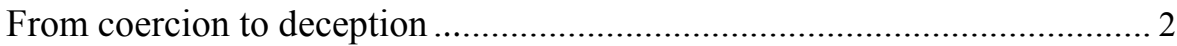

Research-based development of police interview methods ............................ 3

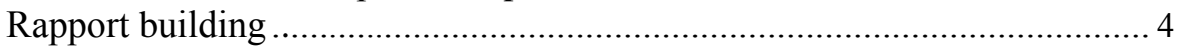

Attitude function and automaticity in police interviews ............................. 5

TRAUMATIC FACTORS, THE CRIME AND THE INTERVIEW ..........10

Theoretical aspects of trauma, stress and coping ......................................10

Traumatizing crimes, the suspect and the police interview.........................12

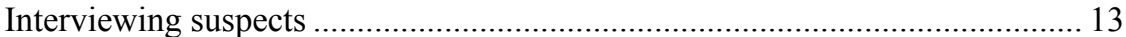
Interviews with suspects of sexual and violent crimes ...................................... 15

Traumatized crime victims and police interviews.......................................16

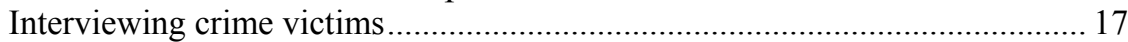

Traumatizing crimes, the police officer and the interview ….......................20

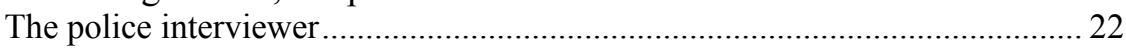

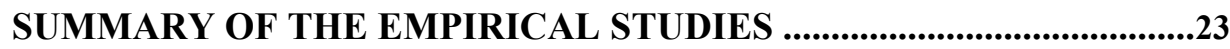

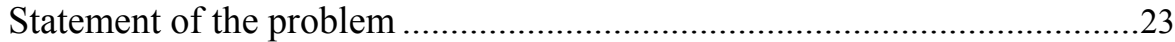

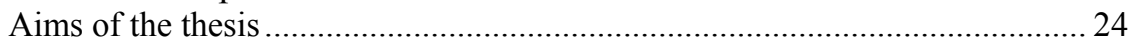

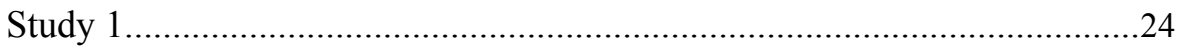

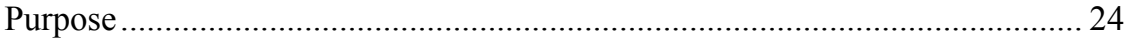

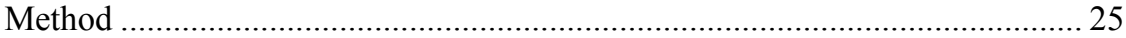

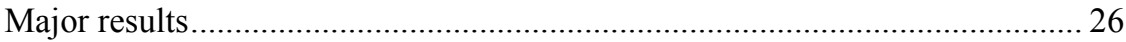

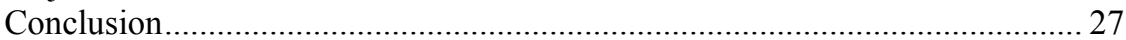

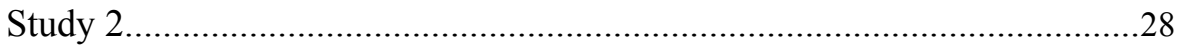

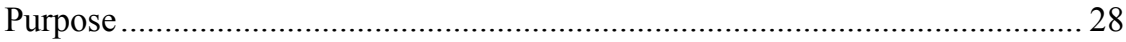

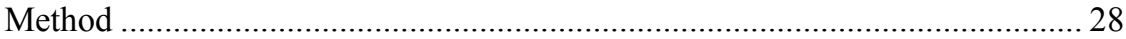

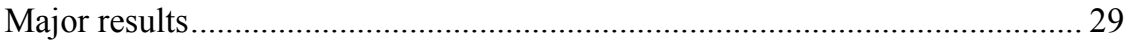

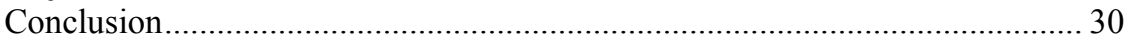

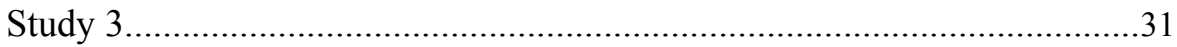

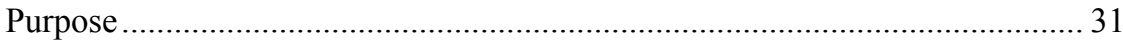

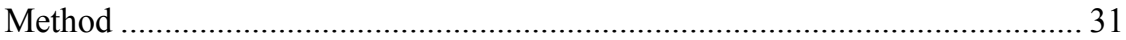

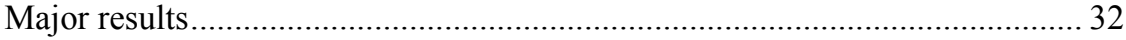

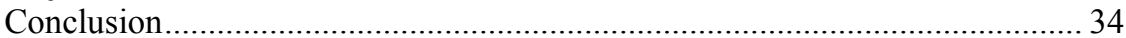

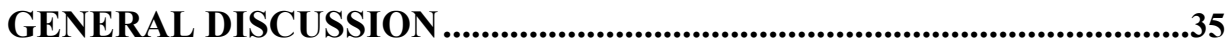

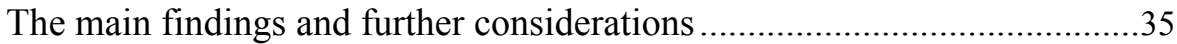

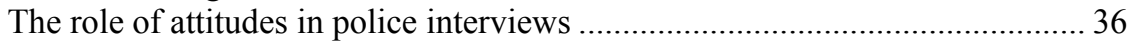

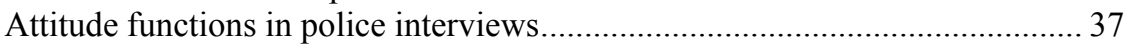

Attitude automaticity in police interviews.......................................................... 39

Rapport building, attitude functions and automaticity in police interviews ...... 41

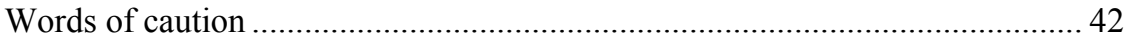

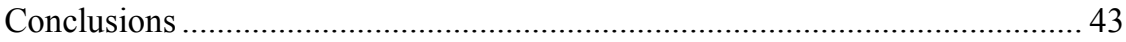

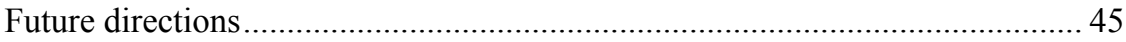

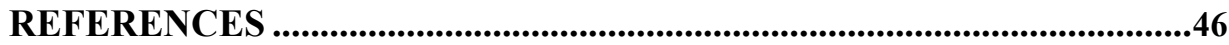





\section{THE CHANGING NATURE OF THE POLICE INTERVIEW}

Fundamental to the success of a crime investigation is the information the police investigator gathers from different sources. This information must describe what and when a crime occurred, how the crime was accomplished, and why the crime was perpetrated. Without this information, crime victims' human rights cannot be safeguarded, the suspected person cannot be sued, the involved people cannot be completely rehabilitated, and the investigation will most likely be dropped. Evidence can be of a technical nature, for example, fingerprints and DNA profiles. From technical evidence, the investigator may find an important conclusion in the sequence of the crime event, but such technical evidence does not tell the whole story. Moreover, investigations often lack technical evidence and under such circumstances the content of police interviews with crime victims, witnesses and suspects becomes very important, often completely deciding the success of a given crime investigation. To describe the criminal act, the consequences of the crime and the intent of the perpetrator, the crime investigation needs accurate descriptions from the crime victim, possible eyewitnesses, and the suspected offender. The police interview is therefore an important tool in gathering descriptions from those who have any knowledge of the criminal act.

A good police interview is conducted in the frame of the law, is governed by the interview goal, and is influenced by facilitating factors that may affect the elicited report (Yuille, Marxsen \& Cooper, 1999). In this respect, the characteristics of the interviewer are a dimension that is likely to affect the outcome. Seeing the importance of the police interview, its substance, and signification for the legal process, it is important to study what interview methods police officers use. It is also important to study how crime victims, witnesses, and suspects perceive these police interviews as well as under what circumstances these interviewees experience that they are given a mental space that facilitates an exhaustive narration. It seems reasonable to assume that the interviewees' experiences may differ, and for that reason, it is important to study how crime victims as well as suspects perceive the police interview. Undoubtedly, most crimes of violence and sexual offences cause emotions that likely affect crime victims as well as suspects. Even police officers may be affected by exposures to stressful crime events and by listening to narration about such crimes.

The present thesis investigates, describes, and discusses the variation in police interviews in Sweden. By way of introduction, a historical review is presented, describing different police interview methods. Next, current research on police interview studies is described. Subsequently, police interviews with crime victims are compared with interviews with suspects. Finally, the question of the extent to which police officers' exposures to stressful events may influence their attitudes towards interview crime victims and suspects is investigated. 


\section{From coercion to deception}

From antiquity to the first half of the twentieth century, legal actors have used acts of cruelty to discover criminal facts. Suspects have tried to hide their knowledge by silence or lies, and historically, the method chosen to obtain confessions has been the use of physical and mental force. Münsterberg (1908/1923) argued that threats and tortures have been used all over the world and for thousands of years to force suspects to confess. The term "third degree" was introduced in 1900 to define serious questioning of a prisoner through mental or physical torture to extract confession (Merriam-Webster, 2004). From the first decades of the twentieth century, Münsterberg (1908/1923) described that the "third degree" - through use of the dazzling light, the cold-water hose and the secret blow - was still being used by the police. The contemporary public opinion was firmly against such methods, and the public was convinced that the "third degree" was ineffective in bringing out the real truth from suspects. Up to the early 1930s and perhaps longer, the police interview tactic was generally marked by coercion (Leo, 1992).

In Sweden, Hassler (1930) stated that the form for the police interview should be inquisitorial, marked by questions from the police interviewer. The suspect should, in the absence of inflicted pain, threat or deceit, be induced to a voluntary confession. Peixoto (1934) pronounced, from a Brazilian view, that the "third degree" was inquisitorial and of doubtful value. In the 1930s and 1940s, the use of coercive interviewing methods began to decline (Leo, 1992). It was recommended to Swedish police officers that they should try to win the interviewee's trust. Subsequently they should let the interviewee provide a continuous narration before the police officer began to ask open-ended questions (Leche \& Hagelberg, 1945). Leche and Hagelberg also emphasized the necessity for police officers to understand people's emotions and reactions, to have knowledge about the function of the human memory, and to understand how a statement could be affected by different circumstances.

In order to secure the truth and to judge a witness's veracity, Gerbert (1954) stressed the need for understanding a witness's personality. Gerbert stated that some tense witnesses, who appeared to be guilty, were instead reacting to the interview, and these witnesses became relaxed only when they were assured that the interview would be conducted in a fair and impartial way. Moreover, Arther (1955) found that blood pressure may rise in response to relevant questioning and that this may sometimes indicate innocence.

In the 1960s, deceptive techniques, tactics and stratagems emerged within the realm of the police interview. These methods were based on an uncritical and subjective use of psychological knowledge. Zimbardo (1967) found that methods manuals were principally written by police officers, detectives, or former staff members of scientific crime laboratories. One such manual that discusses psychological tactics and methods with respect to interview suspects is the book Criminal Interrogation and Confession by Inbau, Reid and Buckley 
(1962/1986). This manual uses a conscious persuasive tactic to create a conversational rapport in order to win the suspect's trust and obtain the suspect's confession. That is, the interviewer leads the suspect into an atmosphere of confidence, and shows sympathy and understanding for the actual criminal behaviour. The interviewer sells the advantage of a confession, cajoling the suspect to a point where close rapport is established. Then, the interrogator puts the suspect in the position of choosing between two possible positions, both of which are incriminating. The suspect may be asked whether this was the first time it happened or whether the acting had occurred before. Whatever alternative the suspect chooses, it will lead to an incriminating confession. Because of the inherent persuasive power of the technique, Inbau et al. (1962/1986) suggested that this interrogation technique should be used only when interrogators are convinced that the suspect is surely the person who has committed the crime.

Several researchers have found a high risk in using persuasive interview techniques, such as that Inbau et al. (1962/1986) recommended, because they may generate false confessions (e.g., Gudjonsson, 1992, 1994, 2003; Münsterberg, 1908/1923; Zimbardo, 1967). Gudjonsson defined three types of false confession: voluntary, pressured-internalized and pressured-compliant (Gudjonsson, 2003). The voluntary false confession may emanate from an internal pressure, a psychological need to falsely confess a crime. The pressured-internalized false confession refers to a situation in which a person has come to believe, through a police interview, that he or she has committed a crime. A pressured-compliant false confession mirrors a situation in which a person falsely confesses a crime for some instrumental gain, because of the demands and pressures expressed by the police interviewer. Thus, false confessions may depend on confessionseeking procedures and may appear in different circumstances, a notion that Münsterberg (1908/1925) already articulated in the early days of the past century.

\section{Research-based development of police interview methods}

The psychologist Dr Eric Shepherd trained police officers of the London City Police in the early 1980s. Shepherd worked out a script for managing any conversation with any person a police officer would be likely to meet. In the context of this training, Shepherd coined the term Conversation Management (CM), which means that the police officer must be aware of and manage the communicative interaction, both verbally and non-verbally (Milne \& Bull, 1999). CM comprises three phases: the pre-, the within- and the post-interview behaviour. In the within-interview phase, the interviewer is encouraged to pay attention to four sub-phases: Greeting, Explanation, Mutual Activity and Closure, abbreviated as GEMAC (Milne \& Bull, 1999). The greeting phase concerns an appropriate introduction of the interviewer, which means establishing rapport. In the explanation phase, the interviewer must set out the aims and objectives, and develop the interview further. Mutual activity concerns the elicitation of narration from 
the interviewee and subsequent questions from the interviewer. Closure is the important phase in which the interviewer should create a positive end of the interview, aiming at mutual satisfaction with the content and performance of the session. CM was consistent with the Police and Criminal Evidence Act introduced in 1984 in the UK, and after this followed further research into the realm of the police interview. The key to continuing into the explanation and the information-gathering phases of $\mathrm{CM}$ seems to be establishing rapport.

\section{Rapport building}

Rapport can determine whether an interview will fail or succeed. Rapport certainly makes it easier for a crime victim to provide information in a police interview, which is exemplified by this female rape victim's experience of her police interviewer (Holmberg, 1994).

He got me to describe and talk about the details in such an intimate way, like you wouldn't even do with your best friend. It didn't seem like he was being nosy either. He did it for my sake because it was necessary for $m e$, not just for the investigation (p. 36).

From such a statement, it can be assumed that this police interview signified rapport, which likely contributed to the victim's willingness to narrate about the crime event. Thus, establishing rapport is essential to the police interview (see, e.g., Fisher \& Geiselman, 1992; Kebbell, Milne \& Wagstaff, 1999; Milne \& Bull, 1999; Shepherd, 1991; Shepherd \& Milne, 1999; Shepherd, Mortimer, Turner \& Watson, 1999). Fisher and Geiselman (1992) stressed that rapport is established by personalizing the interview and showing empathy, while Milne and Bull (1999) emphasized attention and active listening as necessities for rapport building. Collins, Lincoln and Frank (2002) investigated the results of the three interviewer-attitude conditions, rapport, abrupt and neutral. In the rapport condition, the interviewer showed a gentle, relaxed and friendly approach, and used the interviewee's name. In the abrupt condition, the interviewer spoke in a staccato and hasher tone, did not refer to the interviewee by his or her name, showed a stiff body posture and indifference, except to conducting the experiment. The neutral approach implied that the interviewer should be as neutral as he or she could possibly be in all behavioural aspects. Results showed that participants clearly recognized the rapport approach and felt that more rapport had been established compared to the other conditions. In the rapport condition compared to the abrupt and neutral approaches, the interviewees provided more correct items from the dramatic video-clip all participants had previously seen. Additionally, there was no increase in incorrect information in the rapport condition. One may see the neutral approach in the Collins et al. study as congruent with the suppression condition in the study by Butler, Egloff, Wilhelm, Smith, Ericson and Gross (2003). The participants saw a film and were subsequently asked to discuss the film in dyads. During the discussions, one subject in each 
dyad from the so-called suppression group was instructed, via headphones, to suppress his/her feelings and not show any emotions at all. The control group did not receive any instructions. Result showed that suppressors reacted with an increase in blood pressure, and felt less rapport during the conversation than did the controls. The partners of suppressors liked their partners less in comparison with controls, and they were uninterested in ever speaking with them again. Butler et al. (2003) concluded that, at least in some contexts, suppressing emotions disrupts communication and is obstructive to efforts of establishing social bonds.

Ridgeway (2000) argued that rapport exists inherently in a communicative process that comprises ethical parameters. Tickle-Degnen and Rosenthal (1990) offered a conceptualization of rapport as a construct of non-verbal prototypical components that do not fall into mutually exclusive categories. These components are attentiveness, positivity and co-ordination, the relative weight of which changes according to the individual's experience of changing levels of rapport in the development of a relationship. From an insider perspective, attention involves feelings of mutual interest and focus, positivity comprises feelings of friendliness and warmth, and co-ordination involves balance and harmony (Hendrick, 1990). Thus, Hendrick stressed that the insider's perspective concerns the phenomenology of feelings that participants perceive in an interaction. Patterson (1990) questioned how rapport can be distinguished from other constructs, for example empathy, and Tickle-Degnen and Rosenthal (1990) declared that rapport is an intrinsic interactional phenomenon of mutual feelings. Without such feelings, genuine rapport cannot exist.

Thus, when rapport is established, interviewees provide more correct information than they do without rapport, and in the latter condition, partners react with dislike and show reluctance to create social bonds. This perspective indicates that attitudes may have an automatic function in rapport building. Researchers have pointed out the need for research regarding the relationship between attitudes and the police interview (LeDoux \& Hazelwood, 1985; Sear \& Stephenson, 1997; Stephenson \& Moston, 1994).

\section{Attitude function and automaticity in police interviews}

Depending on how they are perceived, attitudes can indicate whether or not rapport has been created in a police interview. Attitudes comprise values, and people express their attitudes through complaisance and deprecation, likes and dislikes. Eagly and Chaiken (1998) defined an attitude as a psychological tendency that expresses an evaluation, through some degree of favour or disfavour concerning a certain entity. Moreover, an attitude exists as an internal state of a person and lasts for a varyingly long period of time. This implies that attitudes are studied in terms of observable responses, for example, a rape victim's narrative response to a police interviewer who has established rapport in the interview. A person is biased towards favourable or unfavourable responses depending on how an attitude object (e.g. an interviewee, an interviewer or the interview itself) 
is evaluated, which may affect an individual's inclination to take part in a rapport-building process. Yuille et al. (1999) stressed that police interviews should be conducted in a manner that minimizes any negative impact on the interviewee, both personally and emotionally. Such an approach infers the establishment of rapport. Rapport may "open doors" and "shut doors" and under threatening conditions attitude responses appear automatic, which this convicted rapist's declaration of his police interview indicates (Holmberg, 1996).

It was easier for me to talk to people who acted properly because people who interview people, they should not punish you, but they can do so just by their way of talking, showing their hate for me as a human being, and at that moment you turn around and return their hate (p. 35).

This quotation indicates that when the rapist perceived attitudes of being properly treated, the attitude response functioned automatically by making it easy for him to talk. The quotation also indicates that when a person perceives an interview marked by hate, the attitude response may function automatically, causing that person to show avoidance and return the hate. In both cases, the attitudes function as evaluative responses. Some attitudes may emanate from a direct or even an indirect experience a person has with his or her attitude object (see, e.g., Eagly \& Chaiken, 1998). Regardless of which stimulus is involved, individuals can evaluate it as good or bad in a fraction of a second. In the wide meaning of the capacity to immediately identify objects as positive or negative, this implies thus that attitudes have an inherent function (Eagly \& Chaiken, 1998). Chen and Bargh (1999) revealed that positive attitudes serve as an approaching orientation towards objects, whereas negative attitudes generate avoidance.

Katz (1960) proposed four attitude functions: the instrumental (which is also termed as an adjustive or utilitarian function), the value-expressive function, the knowledge function and the ego-defensive function. The instrumental function comprises the individual's strivings to maximize his or her rewards in his or her external environment and to minimize punishments. This function may be exemplified by the rapist who felt properly treated and, in the view of being properly treated in the future, began to talk about his crime. Similarly, a police officer's striving to conduct good "fruit-bearing" interviews with the purpose of being acknowledged as a competent interviewer may also be explained by the instrumental function. This function depends upon present or past experiences of the outcome and of the use of the actual attitudinal object. Obviously, the clarity, consistency, and nearness of satisfying rewards and punishments are crucial factors in the acquisition of a certain attitude. Demski and McGlynn (1999) studied attitudes towards parolees and found that these attitudes, based on beliefs and practical reasons, were associated with the instrumental/utilitarian function.

The value-expressive function is the second attitudinal function of Katz (1990) that serves the promotion of an individual's central values. Satisfaction plays an important role in this function, in the individual's striving to let cherished beliefs and self-image grow. This function gives clarity to the self-image 
of the individual and moulds that self-image closer to the inner desire of the individual. This may be exemplified by the police officer who performs the interview properly, which may lead to his or her feelings of satisfaction with being a skilful interviewer.

The third function is the knowledge function, which involves the individual's striving to seek meaning and constructive knowledge of what the individual faces in a changing world (Katz, 1960). This promotes the formation of standards for understanding the world. This function may be exemplified by the officer who, with the knowledge of a forthcoming case involving a person suffering from borderline personality disorder, reads a great deal about this disorder. Other attitude researchers have described this knowledge function as a frame of reference, usable for interpreting what a human being may face in his or her daily life (see, e.g., Eagly \& Chaiken, 1998).

The situation in which the rapist perceived hate on the part of his interviewer and returned that hate is applicable to the ego-defensive function (Katz, 1960). This function is linked to a mechanism of ego defence, which comprises the individual's avoidance of the internal or external realities that the world presents. There are two types of defence mechanisms, whereof the first is more socially handicapping, leading to the function of denials and complete avoidance. The second type of defence is not as handicapping as the first type and works more for distortion than for denial. It has to be pointed out that the actual attitude is not created by the attitude object, but by the emotional conflicts of the individual. This can be exemplified by a police officer who is overwhelmed by previously stressful experiences, and is now investigating a rape case in which he shows avoidance in the encounter with a suspect. Such avoidance may be shown by the demeanour of the interviewer, and interpreted as hate by the rapist, who then returns the hate. Katz (1960) emphasized that people are often unaware of their defence mechanisms and that ego-defensive attitudes are highly resistant to change.

Lapinski and Boster (2001) examined 129 students' ego-defensive functions from a process perspective and formulated a model. The model suggests that individuals who receive threatening messages generate more negative and less positive thoughts than do individuals who receive non-threatening information. The thoughts that emanate from the received message have a message discounting impact. This means that many negative thoughts and few positive thoughts generate more message discounting than does the opposite condition. Discounting message content generates attacks on the message source, thereby affecting the individual's attitude formation. Lapinski and Boster's result showed that the counter-attitudinal messages of a highly ego-involved character are perceived as threatening. A predominance of negative thoughts about a message, compared to positive thoughts, affects a person's response to threatening messages. This, in turn, increases the likelihood that the person will discount the message's information, and as this information is increasingly discounted, the probability of source derogation increases. When source derogation increases, 
subsequent attitude formation becomes less in line with the message assertion. Lapinski and Boster concluded that this process describes the ego-defensive function of attitudes. La France and Boster (2001) argued that efforts to change an ego-defensive function are difficult, because mere exposure to such an attitude object increases the respondent's defensiveness.

Katz (1960) stated that when a hungry man talks about food, and expresses a positive attitude towards his favourite dish, this implies that attitude arousal has occurred as a consequence of the man's need. Similarly, when a rape victim talks about what has happened to her, and expresses a positive attitude towards working through it, this implies that attitudinal arousal has occurred as a consequence of the woman's needs to unwind. On the other hand, when a crime victim's or an offender's initial attitude towards narrating and taking part in rapport-building no longer satisfies the actual need for narrating, the individual becomes frustrated. This frustration arises because the initial attitude no longer serves its purpose. In such situations, it is likely that the person will modify the old attitude or replace it with a new one, and hereby an attitude change has occurred (Katz, 1960). Attitude change always begins with a problem of dissatisfaction, that is, incongruence between the need and the attitude, or an experience that the actual coping process has been thwarted. The perceived incongruence may lead to a learning process resulting in an attitude change.

Eagly and Chaiken (1998) argued that Katz's proposition about the function of attitudes shows how attitudes may dictate the formation of social encounters, and how their formation and activation may be controlled. The information-gathering procedure in a police interview is sometimes like an automatic statement-taking activity, and at other times it is more like an interview process (Clarke \& Milne, 2001). Statement-taking seems to be more automatic than interviewing, which entails a controlled process based on knowledge.

When a police interviewer consciously uses an interview strategy to enhance an interviewee's possibility of providing information, the interviewer is likely controlling his or her behaviour. Control may be seen as a conduit for the ways in which determinants of behaviour express influences (Wegner \& Bargh, 1998). Controlling something implies that the individual can consciously manifest an effect on this something in a certain direction. The control process needs incoming information from outside the control system and this is termed input, for example, an interviewer's perceptions of an interviewee's reactions. The input, in turn, sets the direction of the control criterion. The input awakens a need or request for control actions to meet the control criterion. The behaviour that will meet the criterion is termed the output of the control process, for example, an interviewer's behaviour to pay attention to the traumatized interviewee's needs. In cases where the process proceeds independent of the system's output, social theorists talk about an open-loop control system or a feed-forward system. For example, taking an unprepared statement from a crime victim can be seen as an open-loop system, because the action does not say anything about the way to gather information. On the other hand, when conscious control actions are de- 
pendent on the system's output, it is termed as a closed-loop system or feedback system. For example, conducting a well-prepared cognitive interview (Fisher \& Geiselman, 1992) with a crime victim can be seen as an action in line with the closed-looped system, because the interview ends when the crime victim has provided all available information. Wegner and Bargh (1998) argued that the open-loop control system mirrors more closely an automatic process than a control process.

The offender who perceives hate in the way his or her interviewer talks and who directs hate towards the interviewer in return (cf. the quotation of the rapist above, p. 6) provides an example of an attitudinal ego-defensive function that appears automatically. Besides the control system operating at a conscious level, two forms of automatic processes exist (Wegner \& Bargh, 1998). The first process comprises the initial perceptual analysis of the environment, which also manages attentional screening. Such screening may cause an interviewee to perceive negative attitudes in the interview, when his or her ego-defensive function automatically screens a positive stimulus. The other process comprises efficient attentional and behavioural skills that are initiated consciously and attentionally. This may be exemplified by the skilled interviewer who consciously, and with demands of limited attentional resources, intentionally activates a higher alert. In such a situation, an interviewer may automatically recognize subtle stimuli indicating a need for help and support in order for the interviewee to unwind and provide information. Regarding automatic processes, researchers have identified unintentional influences on perception that take place outside human awareness and that are efficient in their use of little if any attentional resources (see, e.g., Wegner \& Bargh). These automatic processes are efficient in that they consume little or no resources, allowing them to operate in parallel with other processes. They cannot be stopped once started because of their uncontrollability. Faced with an attitude object, attitude activation may occur automatically, and given this automaticity, it may be more consistent in influencing behaviour than what a controlled process would allow. The regularities of an individual's life are taken over by automatic processes, with the advantage that more of that person's limited cognitive resources are spared to handle novel and complex situations (Todorov \& Bargh, 2002). These authors have also found a relation between environmental stimuli that automatically affect a person's perceptions and aggressions and hostility (e.g., the rapist who perceived hate and returned hate, p.6). Also found was a similar relation between environmentally caused behaviour and aggressions and hostility. All automatic processing is conditional and appears in a variety of forms related to the specific environments or conditions (Wittenbrink, Judd, \& Park, 2001).

Attitude formation may occur automatically during an instance of multitasking, when the individual deals with an attitude object at the same time as he or she performs an un-evaluative control process (Wegner \& Bargh, 1998). Automatic attitude formation may also occur by classical conditioning, which also may be seen as a spreading attitude effect (Meijnders, Midden \& Wilke, 
2001; Walther, 2002; Wegner \& Bargh, 1998). This occurs when a novel attitude object becomes related to another object or situation that has already been evaluated as positive or negative.

In sum, automatic processes are very fast and efficient, grow out of the individual's frequent and consistent experience, operate outside the need for conscious guidance, set operations to the conditioned needs, and while some require an act of a conscious will, others are trigged by the environment. Such automatic processes may generate attitudes of hostility and acrimony towards the police, as a convicted child molester expressed regarding his police interview. The child molester said, "He didn't ask a question, in fact, once he asked me, 'why do you think she (the child) acts like this.' He laid it down, he said to me like this, 'what you have done here', he said, 'that's serious" (Holmberg, 1996, p. 34). A statement such as this indicates a confrontational interview that will likely cause stress and will possibly be influenced by the stress awoken. Stress may have a negative influence on police interviewing. Crimes of violence and sexual offences cause emotions and negative stress that will presumably affect the police interview and its outcome. This relationship between stress and interviewing will be discussed in the next section.

\section{TRAUMATIC FACTORS, THE CRIME AND THE INTERVIEW}

This thesis discusses the police interview with respect to very serious crimes such as murder, aggravated assault and rape. These crimes may deeply affect the individuals involved both physically and psychologically, and have been reported to have long-lasting consequences for the stricken human being (see, e.g. Blackburn, 1993; Dahl, 1992; Kilpatrick, Resnick, Saunders \& Best, 1998; Pollock, 1999). Moreover, besides the direct involvement in violent or sexual crimes, anyone who engages empathically with trauma victims can be, through a cumulative process, affected by vicarious traumatization through listening to traumatic material while fulfilling a caring role. It is also obvious that the effects of having murdered another person, or committed sexually or non-sexually aggravated assault against another person may burden the individual during the police interview. The individuals involved, in the aftermath of painful crimes, comprise crime victims, suspects, witnesses, police officers, relatives and those nearest to the stricken individual as well as other legal and rehabilitation personnel. This thesis considers the experiences of crime victims, and suspects, but also those police officers who have to deal with the trauma of the crime, each from the perspective of his or her own specific role and situation.

\section{Theoretical aspects of trauma, stress and coping}

Classen and Koopman (1993) defined trauma as an abrupt physical disruption in an individual's ordinary daily experience that often causes a loss of control over the body, and may be perceived as objectification of the body. Frightening ex- 
periences, such as natural or human-induced disasters, lead to physiological and psychological experiential discontinuities. The traumatized individual becomes helpless because he/she experiences the world as unpredictable, threatening and assaulting, which fundamentally threatens the individual's sense of self. The traumatic event is extremely alien and, as such, an experience outside the range of ordinary life, with respect to which "the mind has little immediate resources but to distort the event or to banish it from consciousness" (Classen \& Koopman, 1993:178). The perceived helplessness is often paralleled by pain and fear that emanate from the stricken individual's sense of having little or no control over what happened.

Regarding the term stress, researchers have adopted a stimulus-response perspective, because there has been a relationship observed between the environment and responses, for example, anxiety (see e.g., Jones \& Bright, 2001). A prominent definition defines stress as a transactional approach (see, e.g., Goldberger \& Breznitz, 1993). An interviewee who shows anxiety-related reluctance to narrate about his or her experiences causes stress in the police officer in his or her efforts to create a positive narrative environment. In this perspective, stress is seen as a specific relation between the human being and the environment that is perceived and evaluated as a strain that may exceed the individual's coping resources. Moreover, Huether, Doering, Rüger, Rüther and Schüssler (1999) argued that stimulus and response are closely linked components that interact and mutually affect each other in a process described as the stress reaction process (SRP). A SRP is triggered by a physiological and/or a psychosocial, imagined or anticipated strain, for example, a suspect's reluctance to admit a crime and narrate about this crime due to the uncertainty of what will happen next. The SRP implies continuous interaction and feedback between cognitive and emotional appraisal of the strain and its meaning for the stricken person. From this emanates a sequence of physiological, cognitive, emotional and behavioural reactions that induce an individual coping behaviour relevant to the perceived situation. For that reason, it is important that a police interviewer be receptive and provide space for the interviewee to ventilate psychologically loaded issues in the interview. These issues are not necessarily investigative facts. For example, a female suspect, also a mother, may worry very much about her children, which stresses her, and hinders her from even thinking about providing information to the investigation. If she has the opportunity to ventilate her anxiety, it is likely that she will see her situation from another, somewhat less anxious perspective. When the individual can manage to terminate the SRP, a controllable SRP is established, and when the SRP is non-manageable and cannot be terminated, an uncontrollable SRP is apparent. Huether et al. stressed that an uncontrollable SRP is existent when there are no resources, no adequate coping strategies that can be applied to eliminate the stressor.

Thus, the definitions of trauma and stress are congruent in the sense that the experience of a certain event causes an unbalance between the perceived 
demands of the event and the perceived resources at the individual's disposal in the situation and its aftermath.

\section{Traumatizing crimes, the suspect and the police interview}

The experiences of committing a serious crime of violence or a sexual assault, and its psychological aftermath, may follow the individual into the police interview room. Research on the aftermath of commitment of a crime appears to be less extensive than that on criminal victimization. However, Adler, Mueller and Laufer (2001) stated that voluntary manslaughter has one common denominator. That is, the murderers have been shocked, frightened, concentrated or intoxicated during their act to an extent that grossly reduced their awareness of the unlawfulness of their behaviour. Thus, the criminal conduct may cause posttraumatic symptoms that may develop into a post-traumatic stress disorder (PTSD). The causal stressor of PTSD is a traumatic event in which the individual has experienced a disaster or a catastrophe that has been perceived as extremely threatening (DSM IV; American Psychiatric Association, 1994). Clinical indicators of PTSD symptoms include: dissociation, nightmares and reexperiencing trauma/flashbacks, avoidance of reminders of trauma, anxiety/hyperarousal, and impairment in social and occupational functioning. PTSD has an onset at any time after the trauma, and the duration of the symptoms must be present longer than one month. Pollock (1999) studied 80 murderers who had confessed their crime and found that $52 \%$ were diagnosed as having PTSD. Eighty-two per cent of these PTSD-diagnosed men had experienced the murder as traumatizing and $70 \%$ of the diagnosed cases had no experience of previous trauma. Moreover, reviews of the literature on violent behaviour reveal a link between impulsive violence, previous trauma, and that these offenders have depressive symptoms and an unstable sense of self in common (see, e.g., Blackburn, 1993; Cartwright, 2001; Dutton, 1999). When confronted with videotaped scenarios of a woman asserting abandonment and independence from a man, the batterers showed exaggerated arousal, anger and anxiety in comparison with a male control group (Dutton, 1999). Furthermore, wife assaulters assessed using the Millon Clinical Multiaxial Inventory (MCMI-II) have shown peaks in avoidance, passive-aggressiveness and borderline personality disorder congruent with post-traumatic stress disorder diagnosed Vietnam veterans. There are also findings suggesting that violent men lack a variety of social information processing skills, that is, they are unable to generate competent responses and more likely to react aggressively when confronted with marital conflicts. Studies of incarcerated rapists assessed using tests from the Minnesota Multiphasic Personality Inventory (MMPI) have indicated that these men's characteristics are closer to violent offenders than to other sexual offenders (Blackburn, 1993). Hostility, irritability, impulsivity, avoidance of close involvements, poor social judgements, and conflicts with authorities have been found to be evident among rapists in general. A similar MMPI-test on incarcerated child molesters indicates 
characteristics of high self-alienation, anxiety, feelings of inadequacy and insecurity, and inhibition of aggression (Blackburn, 1993). It is obvious that the effects of having murdered another human being, or of having committed sexually or non-sexually aggravated assaulted, together with psychological deficits may burden the individual during interviews about such serious crimes. Gudjonsson (1992) claimed that an offender, faced with the police interview, perceives that his freedom is at stake, penalties become realities, and his self-esteem and integrity are adversely affected. The author pointed out that these men, in a negative emotional state, may misinterpret interactional cues, be less likely to be forthcoming, and therefore less inclined to interact in a rapport-building process. It is obvious that suspects may suffer from psychological distress when they are interviewed. The next section will elucidate the police interview with suspects.

\section{Interviewing suspects}

To facilitate the communicative interaction between a police interviewer and a suspect, Shepherd (1991) emphasized the importance of the interviewer showing human feeling towards suspects, and advocated ethical interviewing (EI). Shepherd argued that the EI approach lends itself to professional investigations. It also facilitates an investigative quality associated with a greater degree of success in crime prevention, detection, and conviction of guilty criminals. This approach rests on ethical principles, signifying that the individuals show respect and treat each other as equal human beings with the same rights to dignity, selfdetermination, and free choice. It also emphasizes empathy, which means treating each other from the perspective of mutual understanding. However, showing empathy and compassion was the lowest rated interviewing skill among specialist investigative interviewers (Cherryman \& Bull, 2001).

After observations of 400 video recordings and 200 audio recordings of British police interviews, Baldwin $(1992,1993)$ emphasized the need for professionalism. In the term professionalism, Baldwin included the use of fundamental rules of sound interviewing practice. Such professionalism provides a fair and calm interview in which suspects may express their positions. Additionally, professional police interviewers must also pay attention to the suspects' responses, avoid harrying tactics and coercion. Thus, an open-minded interviewer gives suspects time for reflection and the opportunity to express their points of view. Moreover, professional interviewers establish rapport and listen actively to the suspects' responses. Many officers showed difficulties in creating rapport with suspects, expressed a confession-seeking approach and tried to persuade suspects to accept a predetermined description of the event. The interviewers did not listen to what was being said, but instead continually interrupted the suspect. Furthermore, unprofessional officers occasionally became unduly flustered, aggressive and provocative. The worst type of interviewer was the one who used a macho style, prided him- or herself and was incapable of recognizing how counter-productive this style was. Baldwin concluded that the competence of the police interviewers was unacceptably low. 
In line with Baldwin's method, Moston and Engelberg (1993) analysed 118 taped police interviews involving a wide range of offences and a wide variety of suspects. The most common interviewing style found was a confrontational and confession-seeking approach that disclosed a rather extensive problem. Often the interviewer directly accused the suspect of having committed the crime and simply asked the suspect to confirm the allegation. When the suspect denied, showed resistance, or used his/her right to be silent, the interviews were frequently undermined by avoidance and closure or persistent questioning. An interviewee can show resistance through a verbal or non-verbal blocking behaviour that obstructs the interviewer's efforts to establish rapport and create an appropriate communication. Such unwillingness often depends on psychological blocks such as anxiety, fear, depression, anger, and antipathy (Shepherd, 1993). Unwillingness may appear when the interviewer fails to orientate suspects sufficiently, because individuals need to know the "route maps" if they are to anchor realities. Resistance may also depend on disruptive talk, inappropriate listening, and inappropriate pacing when the interviewer immediately takes the floor after an interviewee's response, filling pauses, and not allowing time for reflection.

Regarding confession-seeking approaches, Stephenson and Moston (1993) studied 1067 cases and found that in $73 \%$ of these cases, the police interviewers were sure of the guilt of the suspect they interviewed. In cases where the officers evaluated the evidence as strong, 99\% were sure of the suspect's guilt. There was no statistical relation found between the officers' assumption of guilt and interview outcomes. Instead, results indicated that when suspects perceived an advantage in confessing, they tended to do so. Regarding interviewing styles, Stephenson and Moston $(1993,1994)$ discovered a difference between accusatorial strategies and information-gathering strategies. When the evidence was judged as strong, the interviewer used an accusatorial approach. That is, the suspects were accused quite early in the interview, and when the officers found the evidence weak, they used the information-gathering strategy. The latter approach increased the probability of obtaining a suspect's narration about the event.

Somewhat in line with Stephenson and Moston's results, Williamson (1993) identified different ideal styles that the police preferred in interviewing suspects. This study was based on a questionnaire completed by 80 detectives. Two of these styles were characterized as confession seeking procedures and the other two were signified by searches for securing evidence. The first confessionoriented approach, conceptualized as collusive, implies that the interviewer acts in a co-operative, paternalistic, helpful, and problem-solving way. The second confession-oriented style was a dominant one in which the investigators expressed confrontation, impatience and emotional images towards suspects. The third, a strategy of securing evidence, labelled as counselling, comprised a cooperative, unemotional and non-judgemental demeanour. In the fourth style, labelled as businesslike and marked by confrontational, brusque, factual and formal demeanour, the interviewer tried to secure evidence. Williamson's research revealed that interviewers who obtained many true confessions showed a 
positive attitude towards the suspect. They also manifested sympathetic and cooperative behaviour. Dominant interrogators, on the other hand, kept up pressure on suspects through quick questioning. These police officers were regarded as unsympathetic and confrontational towards the suspects, who in turn often responded with resistance and denials. Considering his findings, Williamson found the results congruent with the concept of investigative interviewing (II). II was developed in 1992 under the aegis of the British Home Office and Association of Chief Police Officers and was pronounced as the PEACE model of II (Bull, 2000). The term PEACE implies Preparation, Engage and explain, Account and challenge, Closure and Evaluation, which are seen as important phases in a good interview. The aim of the PEACE model is to obtain evidence through correct and reliable information and to discover the truth in a crime investigation. This model emphasizes ethical principles, which differentiate this method from other coercive and persuasive approaches to interviewing suspects. In the National Evaluation of the PEACE Investigative Interviewing Course, Clark and Milne (2001) found areas requiring further improvement. Regarding interviews with suspects, there were needs for further development of communication skills and a structured examination of the interviewees' account.

\section{Interviews with suspects of sexual and violent crimes}

In line with the aims of the PEACE model, Holmberg (1996) showed that convicted sexual offenders who had admitted their crime described their interviews as a calm, empathic experience. Offenders who denied the crime, however, perceived a great deal of external pressure from their interrogators, who argued in a systemic, condemning and confrontational way. Langfeldt (1993) emphasized that, in the first meeting with a sexual offender, it is important to establish an empathic relation. It is crucial to show empathy very early in the contact with the offender, and to talk about his vulnerability, his pain, and powerlessness. Otherwise, a fruitful, professional contact with a sexual offender will not be achieved. Based on their police experience in interviewing serial sexual murderers, Ressler, Burgess and Douglas (1988) argued that interviewers had to establish a focused interest in the offender and convey respect. A crucial aspect in the interview is to develop rapport, and in order to achieve this, the interviewer must understand the subject's mental world. Moreover, based on discourse analyses of ten taped police interviews with paedophiles, Benneworth (2003) found two interviewing styles, one of which had clear implications for suspect admission. In this approach, the police officer surrenders the floor using open-ended, relationship questions and assists the suspect in recreating an elaborative emotional history that facilitates admission. In the second approach, the officer holds the floor, recounts an explicit sexual narrative, and failing to ask questions, the officer eliminates the suspect's effort to intervene and tell his story, which is related to the suspect's denial.

Thus, faced with the reality of being interviewed, the suspect may likely be affected by post-traumatic symptoms or at least by a negative emotional state. 
Researchers stress the importance of including ethical principles and rapportbuilding in police interviews, because this enhances the possibilities for a suspect to experience a mental space where he or she can provide information about commitment of the crime. Other methods marked by pressure and persuasive tactics are counterproductive. From the perspective of a crime investigation, it is also important to consider how interviews are conducted with persons stricken by crimes (Fisher \& Geiselman, 1992; Shepherd et al., 1999).

\section{Traumatized crime victims and police interviews}

Regarding victims' experiences of the crime and the police investigation, Doerner and Lab (1998) reviewed the victims' physical and psychological costs and argued that crime victims in investigations weigh the pros and cons of their participation. Those who perceive extensive negative consequences (i.e., a secondary traumatization) that overcome their positive experiences (e.g., an experience that the officer understands the victim's situation) are less inclined to become involved in the investigation. This female rape victim's experiences exemplify such a condition (Holmberg, 1994),

I don't think he knew how horrible I felt. Sometimes I wondered why I told him about it at all, I guess I'm still wondering. I'm full of big holes and scars. The more we rooted and poked in it, the worse I felt (p. 37).

Shoham (2000) investigated 90 battered wives' first encounter with the police and found that prominent reasons for withdrawing complaints were the women's thoughts that the police did not treat the case seriously or sided with the assaulter. Another prominent reason for withdrawing was that the women perceived that the police did not have the patience to listen to them, and the women felt that there was no understanding for their situation. Moreover, Stephens and Sinden (2000) found that victims of domestic violence experienced the police as positive or negative depending of the officers' demeanour. When police officers showed attention, concern, listened, were emphatic, sympathetic and helpful, and treated victims with respect, the crime victims perceived this demeanour as positive, because the officers seemed to understand the victims' situation. On the other hand, crime victims perceived negative demeanour when the officer minimized the situation (e.g., by downplaying the gravity of what have occurred), disbelieved the victim (e.g., shown by verbal challenges and accusations), did not care (e.g., unmoved and solely focused on facts), and acted as a macho cop (e.g., by being arrogant and rude). Crime victims who perceived negative demeanour experienced mistrust that undermined the interaction with the police officer; in these cases the victim became alienated. Thus, in addition to possible maltreatment in the aftermath of the crime, crime victims suffer psychological distress from the actual crime that has stricken them.

Extensive empirical evidence shows that a victim of aggravated assault and rape commonly experiences disruptive psychological symptoms immedi- 
ately after these acts of cruelty (see, e.g., Dahl, 1992; Davis, Lurigio \& Skogan, 1997; Doerner \& Lab, 1998; Kilpatrick et al., 1998; Norris \& FeldmanSummers, 1981; Pynoos, Sorenson \& Steinberg, 1993; Renk, 1997; Shoham, 2000). For crime victims who have been seriously injured or threatened with death or serious injuries, specific acute stress symptoms arise almost immediately after such a traumatic event that predict the development of PTSD (GoreFelton, Gill, Koopman \& Spiegel, 1999; Pynoos et al., 1993). Gore-Felton et al. pointed out that observations of acute stress symptoms in relation to crime events led to the formation of Acute Stress Disorder (ASD). Clinical indicators of ASD appear for two or more days within the first four weeks, and the symptoms include: dissociation, re-experiencing trauma, avoidance of reminders of trauma, anxiety/hyperarousal, and impairment in social and occupational functioning (American Psychiatric Association, 1994). PTSD is similar to ASD and the primary differences concern their onset and duration (American Psychiatric Association, 1994). ASD has an onset in the first month and duration for two days up to a month. There is a high risk that an individual with an initial diagnosis of ASD will develop PTSD (Classen, Koopman, Hales \& Spiegel, 1998). Thus, regarding the duration of the symptoms, it is likely that many victims of sexual or non-sexual assault are suffering from ASD or PTSD while being interviewed by the police. With the crime victim's trauma in mind, the next section discusses how to interview crime victims.

\section{Interviewing crime victims}

In the early 1980s, when Shepherd developed conversation management in the UK, Fisher and Geiselman (1992) developed the cognitive interview (CI) in the US as a memory enhancing technique. Studying how police officers conducted their interviews with crime victims and witnesses, Fisher and Geiselman revealed that many officers had no formal training. They conducted interviews according to their intuition - what they had learned on the job or by observing senior colleagues. Written manuals lacked information about how to effectively interview in a memory enhancing way. Fisher, Geiselman and colleagues (1992) revealed that the most salient features of victim and witness interviews showed a deficiency in the interview structure: almost all questions were direct and no memory enhancing assistance was given. Universally, the interviewers erroneously interrupted the interviewees, asked too many direct and short-answer questions and sequenced questions inappropriately. Consequently, the CI was developed on the basis of laboratory experiments, field studies and scientific knowledge of human memory.

The first version of CI was based on memory theories, but soon Fisher and Geiselman (1992) realized the need to include aspects from social psychology and revised the original CI. The revised version comprises several components, and the first, introduction, suggests that the interviewer encourage the interviewee to actively participate in the interview. In this phase, the interviewer develops a rapport with the interviewee by personalizing the interview, express- 
ing empathy, and listening actively. When creating a personal bond, the interviewer may give some personal and biographical information about him- or herself (without being private) to which the interviewee can relate. This phase also comprises an anxiety-reduction component wherein the interviewer conveys his or her interest in maintaining the interviewee's confidence. It could be very helpful to talk about the anxiety and indicate its naturalness as well as to talk about the fact that the experiences the victim or witness may perceive do not mean that the event will occur again. The interviewer instructs and encourages the interviewee to describe everything, even details and trivialities, but not to guess. The next phase comprises a reinstatement of the context of the event. The reason for reinstating the context is based on the knowledge that human beings remember more when they are in the same state or environment as when the event was encoded (see e.g., Baddeley, 1998; Christianson, 1992a, 1992b). By using openended questions the interviewer encourages the interviewee to search through his or her memory from the event and to give a free narration of what comes to mind. It is important not to interrupt the interviewee in his or her narration. When the memory is drained, the interviewee is instructed to give the report in a different order, and thereafter change perspective by adopting someone else's view. Subsequently, the interviewer uses witness-compatible questioning to probe certain facts relevant to the investigation. At the end of the interview, the interviewer reviews what has been reported, allowing the interviewee to check that what has been reported has also been correctly understood. In the closure phase the interviewer collects background information, extending the functional life of the interview because the interviewee will continue to think about the crime event, and finally, creating a positive last impression.

With the aim of maximizing disclosures of crime victims, Shepherd et al. (1999) elaborated CI further, and incorporated aspects from cognitive-behaviour therapy into the CI. The technique was termed as the Spaced Cognitive Interview (SCI) and aimed at helping crime victims in the event of anxiety-hindered narration. The purpose of SCI is to reduce the crime victim's anxiety by prolonged exposure (PE), which means mental re-experiences of the crime event. Mental re-experience through narratives reduces anxiety originating from traumatic experiences (Pennebaker, 1997). Shepherd et al. described a case in which a young woman had been traumatized following an attempted rape. She felt strongly that the man should be stopped, but she did not feel robust enough to tell the police. After two SCI sessions, the young woman was able to give a statement to the police.

A police officer is often the first person a traumatized crime victim meets, and Shepherd et al. argued that police officers conducting SCI are "in a unique position to set in train a healing, expressive process" (1999:139). The authors emphasized that SCI should take place as soon as possible after a crime event has occurred, and in ensuing weeks subsequent SCI sessions should follow. Shepherd et al. also argued that prolonged interviews are memory enhancing. 
Regarding the number of interviews, Brock, Fisher and Cutler (1999) revealed the information-gathering benefits of multiple interviews (i.e., CI).

Yuille et al. (1999) stated that, though many studies have investigated the strengths and weaknesses of eyewitness memory, few provide specific suggestions on how to interview crime victims and eyewitnesses. Yuille et al. pointed out that the $\mathrm{CI}$ is one exception, as the CI protocol has been found useful in reallife settings. The authors argued that the good police interview is governed by the interview goal in accordance with the law and is influenced by facilitating factors that may affect the elicited report. The latter reflects the dimensions of the interview, and police officers need a knowledge base that covers both the goals and the dimensions. Yuille and his collaborators assumed that one goal of the police interview is to gather from a crime victim or a witness the maximum amount of information as well as information of maximum quality. Another goal is to minimize any contamination of what the interviewee remembers from the event and to report these memories in the interview. An additional goal is to conduct the interview in a manner that minimizes any negative impact on the interviewee, personally and emotionally (cf. the quotations on pp. 4 and 16).

One dimension that may affect the accurateness of the interview outcome is the characteristics of the interviewee (Yuille et al., 1999). The interviewee dimension comprises effects concerning the age of the individual, as stage of development (i.e., childhood to adulthood) influences the perception and interpretation of an event and the language used when describing an event. Another component of the interviewee dimension is the motives an interviewee may have to come forward. Yuille et al. argued that many victims are very motivated and some too co-operative, whereas others are unmotivated and uncooperative. The authors warned against drawing a parallel between the motivation level of a subject in an analogue experiment and the motivation of an actual victim or witness of crime. Moreover, victimization has a personal meaning in that it involves surviving a crime event in one way or another. The authors also pointed out that the intrinsic motivation a crime victim may perceive as a consequence of an unpleasant fate may be inexplicable to others. In the interviewee dimension, Yuille et al. also included the personality and culture of an interviewee, which may influence how an event is perceived, interpreted and reported. Furthermore, the role of a victim or witness and the impact of the event may affect the stricken interviewee, who may provide varying amounts of information about an event in focus. Victimization may in some cases (e.g., rape) go beyond the range of normal life experiences and can be assumed to cause great pain in any victim (Dahl, 1992), which must be considered in an interview. However, the reporting interviewee may be affected by cognitive biases in the form of fundamental attribution error (see, e.g., Gilbert, 1998). The second dimension that may affect the outcome of police interviews and that Yuille et al. (1999) formulated is the interview task, which is the process of assessing the credibility of an interviewee's account; this topic is, however, beyond the scope of this thesis. 
The PEACE model, trained and practiced in the UK, has adopted the principles of the CI technique, EI and CM (Milne \& Bull, 1999; Mortimer \& Shepherd, 2000). In 1998, 70\% of the British police officers had been PEACE trained (Clarke \& Milne, 2001). Clark and Milne found that victim and witness interviews were often more like statement-taking exercises and less like an interview process. Ongoing research has also revealed some shortcomings of the PEACE model and suggests pursuing studies focused on what happens during interviews (Clarke \& Milne, 2003).

Thus, when crime victims are going to be interviewed, they may be affected by ASD or PTSD and their possible insufficient willingness to participate in the crime investigation may depend on a rational choice based how they have been treated by representatives of the legal system. Fundamental elements of the victim interview are rapport and interviewer behaviour congruent with $\mathrm{CI}$ and SCI. Crime victims who carry the legal process through to its completion and perceive that they have an impact on their case are usually more satisfied and appear to have a better mental health outcome (Herman, 2003). In crime investigations it is also important to gather information from suspects, not only to receive a second view of what has happened, but also to know the suspect's attention to commitment of the crime. It also seems reasonable to assume that a perpetrator's honest narration may have a healing effect for the crime victim, and for the perpetrator; this may be a first step towards a crime-free life.

\section{Traumatizing crimes, the police officer and the interview}

Police officers are exposed to stressful events, both directly when, for example, entering a crime scene and indirectly by listening to accounts of criminal stressful experiences. Police interviewers have to cope with crime victims, and suspects, but also with themselves, with respect both to previous stressful exposures and to the present crime they are investigating. An important issue is to what extent secondary or vicarious traumatizations from cumulated trauma-related experiences (cf. Pearlman \& Mac Ian, 1993) influence the investigator's attitudes in interviewing victims and suspects.

The extent of perceived stress depends on how challenging the police officer evaluates the event and on what coping resources the officer has to handle the event (Jones \& Bright, 2001). Highly stressful events may involve anything from being the first to arrive at the scene of a traffic accident to acute threat situations in which they themselves are forced to use force (e.g. Herrman, 1989; Karlsson \& Christianson, 2003; Mitchell-Gibbs \& Joseph, 1996). Carlier, Lamberts and Gersons (1997) showed that $34 \%$ of 262 traumatized Dutch police officers had post-traumatic symptoms, and trauma severity was the only predictor of this symptomatology. Salient symptoms three months post trauma were introversion, difficulties in expressing feelings, emotional exhaustion, dissatisfaction with organizational support and, insecure job future. Acute hyperarousal, subsequent traumatic events, job dissatisfactions, brooding over work, and lack 
of social interaction support in the private life 12 months post trauma, were salient predictors of post-traumatic stress symptoms. Unpredictable situations, domestic disputes, the possibility of being injured, and confrontations with armed persons were the highest rated stressors among 39 traumatized Australian police officers (Anshel, Robertson \& Caputi, 1997).

Police officers often listen to crime victims' narration about very painful experiences, become familiar with injustices, and attend to crime victims' emotional needs, which may cause secondary traumatic stress (STS; Salston \& Figley, 2003). Helping traumatized survivors, exposure to their narration and empathy are contributory causes in the development of STS. Daily exposure to sufferings and painful experiences creates stress in professionals (Anderson, Litzenberger, \& Plecas, 2002; Brysiewicz, 2002). Such stress, emanating from encounters with trauma victims, requires professionals to make sense of powerful, often painful, emotions and altered beliefs, which Saakvitne and Pearlman (1996) conceptualized as vicarious traumatization.

Hallett (1996) examined the impact of vicarious traumatizations in law enforcement professionals caused by exposure to human pain and destructiveness. Results showed that maladaptive coping was a major predictor of pathology and distress. Kenny (2000a) defined coping as an economical utilization of the resources the individual has acquired and preserved throughout life. By studying interviews with police officers, probation officers and psychologists working with sexual offenders, Lea, Auburn and Kibblewhite (1999) revealed vulnerability among these professionals. The vulnerability caused by working so close with this offender group comprised a feeling of being seen as having sympathy for sexual offenders. Some of the professionals revealed suffering from personal feelings evoked by certain cases in which the crime victim was of the same gender and age as the professional's own child. These professionals also reported experiences of increased tension, and in the realm of constantly working with dangerous people with poor prognoses, this perceived stress is a compounded stress.

Reiser and Geiger (1984) found that there is a risk when police officers cope by consciously denying feelings such as fear and anxiety. Such denial is particularly full of risks in connection with life-threatening events and development of post-traumatic stress syndrome, which is characterized by guilt, depressive symptoms, withdrawal, alienation and psychosomatic reactions. Distancing oneself from stressful impressions and developing control indicate an emotionoriented coping style whereby the individual accepts responsibilities, chooses flight or avoidance, makes positive re-evaluations and looks for emotional support (Kenny, 2000b). On the other hand, a problem-oriented coping style implies that the police officer confronts the problem, and searches for solutions and social support.

A major factor in coping resources is social support, built upon the strength and quality of a person's social network (Kenny, 2000b). Stephens, Long and Miller (1997) conducted a study on 527 police officers in New Zea- 
land, and investigated the impact of stressful events and social support on PTSD. Stephens et al. found that peer support had the strongest negative relation to PTSD. The researchers concluded that officers who expressed their emotions to colleagues and allowed peers to do the same were less likely to develop PTSD symptoms after stressful exposures. The literature also describes that the type of social support is important. For instance, research has shown that, in the context of an organization, support from work colleagues is more important than that from family and friends (Kenny, 2000b). In a Swedish study about working through stressful experiences, Karlsson and Christianson (2003) found that more than half of the police officers reported that talking about the event with their colleagues was beneficial in reducing their distress. Herrman (1989) argued that police officers traditionally build their own safeguards by associating primarily with other police officers and using humour as a release. However, through conducting in-depth interviews, Pogrebin and Poole (1995) found that police officers guard their emotions and rarely discuss them with anyone. Thus, as police interviewers are frequently exposed to painful narration that may affect them, it is important to investigate the attitudes and the characteristics of the police interviewer.

\section{The police interviewer}

Yuille et al. (1999) argued that interviewer characteristics is a dimension that may affect the interview outcome. This dimension includes the interviewer's ability to keep an open-minded approach, and an ability to establish rapport with an interviewee that improves the prospect that the victim will be forthcoming in the interview. The prospect of keeping an open-minded approach and establishing rapport may be affected by the way in which an officer evaluates the information about a crime victim. In this connection, Koppelaar, Lange and van de Velde (1997) compared 93 law students with 30 detectives and found the detectives to be gentler in their evaluation of rape victims than were the law students. The detectives were also less stereotypical in their beliefs about rape and rape victims in comparison with law students. Koppelaar et al. concluded that detectives may be more sympathetic towards rape victims than people often believe. However, Sear and Stephenson (1997) studied the relationship between 19 police officers' personality characteristics and their interviewing performance and found them to be cold, calculating and dominant towards others. The study also revealed that openness was a major component of interviewing efficacy.

Yuille et al. (1999) stressed that the interviewer must develop listening skills, because it is important to encourage the interviewee to provide information, and consequently, for the interviewer to remain quiet and listen to the provided information. Cherryman and Bull (2001) found that, in the opinion of special investigative interviewers, listening was the most important interviewing skill, followed by preparation and questioning skills. However, listening to traumatized experiences can be painful and automatically activate ego-defensive functions. Croft (1995), as a police officer, argued that some officers may per- 
ceive a reluctance to use the technique of re-establishing the context of the crime event emphasized in the CI. Cognitively reconstructing the event in, for example, a rape victim's mind may be seen, by the police officer, as re-raping the victim and causing heavy anxiety. Croft argued that such emotive considerations may be put forward to justify a police officer's reluctance to help a victim to narrate about anxiety-provoking memories. A crime victim who re-experiences a crime event and who shows pain and anxiety may be perceived as threatening to the interviewer, which automatically activates attitudinal ego-defensive functions. These ego-defensive functions may be expressed as a reluctance to use the reconstructing phase in CI. Furthermore, Stephens and Sinden (2000) found that victims of domestic violence experienced the police officers as positive and understanding or negative, mistrusting and alienating, depending on the officers' demeanour.

Concerning the aspects of questioning techniques, Yuille et al. (1999) emphasized that the interviewer should use the parts of CI and avoid leading or suggestive questions. Yuille et al. concluded that, with a broad knowledge base and the goal and dimensions of the interview in mind, an interviewer has the opportunity to develop professional interviewing skills. The authors also admitted that there are some knowledge gaps concerning the dimension of the police interview and suggested further research on event impact and the motivation aspect.

Contemporary research of today clearly shows an ongoing change in police interviewing: a change from interviews with pressure to an empathic approach based on rapport. Research has also shown that police interviews signified by pressure are still in use. The present thesis will investigate how police interviews are perceived by crime victims and suspects, but also what attitudes police interviewers have towards interviewing crime victims and suspects.

\section{SUMMARY OF THE EMPIRICAL STUDIES}

\section{Statement of the problem}

Research that specifically addresses crime victims', suspects', and police officers' experiences from real-life police interviews concerning aggravated crimes of violence and sexual crimes is quite rare. Researchers have paid relatively little attention to the parties' experiences of the police interview regarding perceived attitudes and subsequent consequences for the outcome of the interview. There are few real-life studies presenting the voices of the parties in the police interview and the factors that affect their behaviour and decisions. Previous research indicates that crime victims' willingness to participate in the legal process largely depends on how they perceive the attitudes of the legal process and its actors (e.g., Doerner \& Lab, 1998; Shepherd et al., 1999; Yuille et al., 1999). Analyses of recorded police interviews with suspects also indicate that attitudes perceived on the part of their interviewing police officers affected suspects' will- 
ingness to participate in the interviews (e.g., Baldwin, 1992, 1993; Moston \& Engelberg, 1993; Moston \& Stephenson, 1993; Williamson, 1993).

One reason to focus on attitudes is that they have been shown to affect people's categorization of events, individuals and objects in their environment. Moreover, attitudes may serve as an automatic process functioning by expressing approach or avoidance towards things appearing in the environment (see, e.g., Eagly \& Chaiken, 1998; Wegner \& Bargh, 1998).

Traumatic experiences from criminal events cause extreme stress in crime victims and perpetrators, and are not only hard to narrate about but also hard to listen to. The pain and difficulties associated with violent and sexual crimes may completely occupy the individual's existence, and may affect the interview outcome. Investigators of violent and sexual crimes, such as homicide, aggravate assault and rape, are exposed to extreme stress by these crimes' intrinsic traumas. Such stress may completely occupy the investigators' everyday life, as one homicide investigator expressed it, "You eat murder, you sleep murder and you even shit murder, it follows you all the time." Thus, the parties' experiences of the prerequisites of the police interview may affect the interview outcome.

\section{Aims of the thesis}

The general aim of this thesis was to explore murderers' and sexual offenders', and victims' of serious violent and sexual crimes perceptions of real-life police interviews in Sweden, as well as police officers' attitudes towards conducting such interviews. More specifically, the thesis has three objectives. One purpose was to investigate the correlation between crime victims' and suspects' perceived attitudes while being interviewed and police interviewing styles as related to interviewees' inclination to provide investigative information. A second purpose was to investigate police officers' attitudes towards interviewing crime victims and suspects, and to investigate whether these attitudes differ in interviews conducted with victims versus suspects. The third purpose was to explore to what extent police officers had been exposed to stressful work-related events during their entire police career, and whether reactions and coping mechanisms from stressful exposures influence police officers' view on interviewing crime victims and suspects.

\section{Study 1}

Holmberg, U. \& Christianson, S-Å. (2002). Murderers' and Sexual Offenders' Experiences of Police Interviews and Their Inclination to Admit or Deny Crimes. Behavioral Sciences and the Law, 20: $31-45$.

\section{Purpose}

Study 1 explored how murderers and sexual offenders perceived the attitudes of their police interviewer and their own responses when they were interviewed as 
suspects of these very serious crimes. The aim was also to investigate whether there existed, from the murderers' and sexual offenders' perspective, certain interviewing styles and responses. In addition, the study analyzed the relationship between perceived police interviewing styles, as well as reactions during the interview, and these murderers' and sexual offenders' inclination to admit or deny crimes.

\section{Method}

Forty-three men who served sentences for murder (one child homicide and 42 adult homicides), and 40 men sentenced for sexual offences (17 for sexual offences against adults and 23 child molesters) participated in a written research interview. A total of 182 convicted murderers and sexual offenders were contacted while they served their time in Swedish prisons. Ninety-four of the inmates $(52 \%)$ returned completed questionnaires, but 11 of these questionnaires were excluded. The excluded questionnaires showed answers indicating that these 11 men had not understood the questions or demonstrated an unwillingness to participate in the study by, for example, completing the questions with a onesided extreme value throughout the questionnaire. The age range of the remaining 83 participants was $20-63$ years $(m=38.9)$, and the term of punishment ranged from 1.3 years to life imprisonment $(m=7.6)$. The lapse of time from the last committed crime (some of the offenders were convicted for a series of crimes) to answering the questionnaire ranged from three months (two offenders) to ten years (four offenders) with a mean of two years and eight months. There are no data about the specific dates on which the murderers and sexual offenders were interviewed by the police. The participants were ensured that their responses in the research interview would be strictly confidential, and they were also informed that the Swedish Law (The Swedish Law, SFS 1974:203) supports such confidentiality. All men who were contacted received a ballpoint pen for their participation.

The questionnaire was construed on the basis of the results and questions used in previous research by Holmberg (1996), Moston and Engelberg (1993), Moston and Stephenson (1993), Shepherd (1991, 1993), and Williamson (1993). The questionnaire included 38 items with 7-point Likert scales, and began by asking participants to rate the extent to which they perceived the attitudes on the part of their interrogator to match a given statement, for example, "To what extent did your interrogator act with calmness and gave you time to comment?" (see Items 1 - 22 in Appendix A to Study 1). Following these rating-questions, participants were asked to rate the reactions they experienced during the interview, for example, "To what extent did you feel yourself respected as a human being?" (see Items 23 - 37 in Appendix A to Study 1). An additional question concerned the extent to which the participants as suspects of murder or sexual offence admitted to or denied the crime during the police investigation. The entire questionnaire took approximately one hour to complete, where after the participants returned it in a pre-addressed and pre-stamped envelope to the public 
authority Kristianstad University (for attention of the first author of this study). The Swedish Law on treatment of offenders in prison states that letters from inmates to public authorities should be forwarded without any censorship (The Swedish Law, SFS 1974:203).

\section{Major results}

Murderers perceived the police interviewers as more unprejudiced, unfettered, and accommodating as compared to ratings made by sexual offenders. The sexual offenders experienced generally more negative attitudes on the part of their police interviewer than what the murderers experienced. However, only a few of the murderers and sexual offenders experienced aggression on the part of their interviewer.

From the murderers' and sexual offenders' perspective, a principal component analysis with varimax rotation revealed two interviewing styles, one characterized by dominance and the other characterized by humanity. In the dominant approach, the murderers and sexual offenders perceived their interviewer as impatient, rushing (the negative loading of calmness), aggressive, brusque, nonchalant, unfriendly (the negative loading of friendly), deprecating (in the article termed as dissociating) and condemning. The humanitarian interviewing style was marked by experiences of co-operations, accommodations, positivity, empathy, helpfulness and an ambition to create a personal conversation.

Principal component analysis with varimax rotation also showed constructs of the participants' reactions to being interviewed. Even here, two factors were revealed, one where the men as suspects experienced themselves as respected and the other where they reacted with anxiety. When the men perceived themselves as respected, they considered themselves as friendly, obliging, acknowledging, not insulted, co-operative, non-aggressive and experiencing confidence. Those who experienced anxiety considered themselves as frightened, stressed, suffered from sleeplessness, became paralyzed, became unconfident and felt themselves as insulted. The humanitarian approach was found to be significantly associated with feelings of being respected, and dominance was significantly related to anxiety.

Regarding admissions and denials, results showed that sexual offenders denied crime more manifestly than murderers during the police investigation. Forty-nine per cent of the murderers admitted their crime during the police investigation versus $30 \%$ that denied crime, and 19\% neither admitted nor denied crime. Corresponding values for sexual offenders were $28 \%$ for admissions and $53 \%$ for denials, and $19 \%$ between admission and denials. Logistic regression revealed a significant positive relation between the humanitarian interviewing style and admitting crime and a weak non-significant relation between a dominant approach and denials. Moreover, logistic regression also revealed a significant positive relation between the murderers' and sexual offenders' experiences 
of being respected and crime admissions, whereas anxiety did not relate to any standpoint on the question of quilt.

\section{Conclusion}

Murderers reported experiences of more accommodating attitudes from their interviews than did sexual offenders, and sexual offenders perceived more negative attitudes than did murderers. One may speculate whether these results mirror different personality characteristics among the offenders. Some studies show that, for example, child molesters are anxious, feel inadequacy and insecurity, and non-aggression, whereas murderers and rapists are generally characterized as impulsive, hostile and aggressive (see, e.g., Blackburn, 1993). The anxiety and negativity in the murderers and sexual offenders may thus be an explanation for these results. On the other hand, sexual offences may be perceived as a greater taboo, a view that may be held by the police interviewers as well as shown by them during the interview.

The study revealed a dominant and a humanitarian interviewing style where the dominant approach signifies an expression of power and unequal rights. The finding of the dominant interviewing style is in line with previous research results regarding coercive and confrontational approaches (see, e.g., Leo, 1992; Moston \& Engelberg, 1993; Moston \& Stephenson, 1993). Such a dominant approach is obviously an example of external pressure that convicted criminals have experienced that police officers use as confession-seeking means (Gudjonsson \& Petursson, 1991; Gudjonsson \& Sigurdsson, 1999). The dominant interviewing style showed a weak relation to denying crimes, which supports previous findings showing that confrontational approaches generate denials (Moston \& Engelberg, 1993; Williamson, 1993).

A humanitarian approach mirrors equality and dignity, that is, a dualistic encounter building on rapport, which is congruent with the ethical principles recommended by, for example, Shepherd (1991). The humanitarian style promotes the possibilities for criminals to express their pain, which Langfeldt (1993) stressed as a necessity in creating rapport with sexual offenders. The humanitarian attitude indicates a police interviewer's inherent interest in a suspect as a human being, the suspect's behaviour and needs as well as a problemoriented approach, comparable with investigative interviewing and the cognitive interview (Fisher \& Geiselman, 1992; Milne \& Bull, 1999). Inherent in a rapport-building process is an attitudinal evaluative process that takes place and functions to signal approach or avoidance, likes or dislikes towards an attitudinal object (see, e.g., Eagly \& Chaiken, 1998).

It seems reasonable to assume that the humanitarian approach signifies rapport through an attitudinal evaluation that generates an approaching behaviour, which in turn may lead to suspects' feelings of being respected, which in their turn confirm and favour rapport. The source of the experienced interviewing style may be the interviewer's behaviour that awoke certain experiences in the interviewee. It may also be the behaviour of the interviewee that awakes an 
interviewer's responses, which in turn are perceived in a certain way by the interviewee.

A significant relation between the humanitarian approach and suspects' admission of crimes corresponds with the therapeutic jurisprudential philosophy, which sees the law and its procedures as therapeutic agents, benefiting human psychological well-being (Petrucci, Winick \& Wexler, 2003). The purpose of therapeutic jurisprudence is to execute legal procedures such that they promote the social and psychological well-being of the individual involved in a juridical action (Wexler, 1996b).

In sum, the present study shows that when police officers interview murderers and sexual offenders, the suspects perceive attitudes that are either characterized by dominance or humanity. Police interviews marked by dominance are mainly associated with a higher proportion of denials, whereas an approach marked by humanity is significantly associated with admissions.

\section{Study 2}

Holmberg, U. (2003). Crime Victims' Experiences of Police Interviews and Their Inclination to Provide or Omit Information. Manuscript submitted for publication.

\section{Purpose}

Similar to Study 1, which explored suspects' experiences of the police interview, Study 2 explored what attitudes and responses victims of rape and victims of aggravated assault have perceived during their interviews. This study also investigated whether there existed, from the crime victims' perspective, certain interviewing styles as well as the victims' reactions during the interviews. In addition, the study aimed to analyse the relationship between perceived police interviewing styles, as well as perceived responses, and the crime victims' inclination to provide or omit information during the police interview.

\section{Method}

This study was based on written interviews collected from female and male crime victims who had been interviewed by Swedish police officers. A total of 432 crime victims were contacted and $178(41 \%)$ victims were willing to participate in the study and completed the questionnaire. Of these victims there were 50 female victims and 2 male victims of rape between 18 and 59 years of age $(m=32.2), 54$ female victims of aggravated assault between 18 and 79 years $(m=36.7)$, and 72 male victims of aggravated assault between 18 and 67 years $(m=33.1)$. Due to the small sample of male rape victims (two), they were excluded from the present analyses. The time between the police interview and the time for completing the questionnaire varied between one month and 33 months. Moreover, there is no information about the skills and training of the police officers who interviewed the crime victims in this study. 
The questionnaire the crime victims received focused on their perceptions and responses at the time when they were interviewed by Swedish police officers. The questionnaire, copied from Holmberg and Christianson (2002), included 43 items with seven-point Likert scales (see Appendix A in Study 1 and Tables $1 \& 2$ in Study 2). The crime victims were asked to rate how they experienced their interviewer concerning perceived attitudes (29 items), for example, "To what extent did your interviewer act with calmness and gave you time to comment?" Following these rating-questions, the crime victims were also asked to rate the emotional responses they experienced during the interview (14 items), for example, "To what extent did you feel respect as a human being?" Besides the questions about perceptions and responses related to the interviews, the questionnaire comprised items asking how many times the participant had been interviewed and the gender of their interviewer. The crime victims were also asked to rate, on seven-point Likert scales, to what extent they managed to narrate about the crime event, to what extent they managed to answer the questions from the interviewer, and to what extent they omitted information during the interview.

\section{Major results}

Results show that $58 \%$ of the crime victims were interviewed only once or twice during the investigation. A majority of the crime victims experienced their interviewers as very calm, obliging, cooperative, helpful, and friendly. Somewhat more than a third of the crime victims rated their interviewer as very empathic and showing a very positive attitude towards them as human beings. There were no gender differences revealed regarding crime victims' perceptions of interviewing attitudes.

Principal component analysis with varimax rotation revealed two interviewing styles, one factor characterized by dominance and one factor characterized by humanity. The dominant approach covered items concerning the crime victims' perceptions of their interviewers as rushed, aggressive, brusque, and impatient. This interviewing style was also marked by unfriendliness, nonchalance, deprecations, and condemning attitudes. The humanitarian approach comprised perceptions of empathy, personal interest and personal conversation, being positive, cooperativeness, helpfulness, obliging manner, and friendliness. Regarding crime victims' reactions while they were interviewed, principal component analysis with varimax rotation revealed three factors of reactions: one marked by anxiety, a second characterized by being respected, and a third signified by cooperativeness. The anxiety factor comprised reactions of being paralysed, frightened, stressed, lost confidence, and suffering from sleeplessness. Being respected was construed by feelings of being seen and acknowledged as human beings without responses of insult and anger. Becoming co-operative as a reaction during the interview was based on feelings of being obliging, cooperative and friendly. The humanitarian approach correlated significantly with feelings of being respected and a co-operative willingness. 
Fifty-one per cent of the crime victims reported that they provided all information from the crime event that they had available while they were interviewed, and thus, $49 \%$ of the crime victims omitted varying amounts of the event-relevant information during their interviews. Logistic regression revealed a significant positive relation between the dominant interviewing style and omitting information, and the humanitarian approach was found to be significantly positively related to crime victims providing all available information in their police interviews. Moreover, logistic regression showed that reactions of anxiety were related negatively, while the other two predictors, respected and cooperative, were related positively to the odds of providing all information. Furthermore, the majority of the cases in which crime victims omitted information led to dropped cases, that is, no prosecution or conviction, whereas the majority of cases in which crime victims provided all information led to prosecution and convictions.

\section{Conclusion}

This study investigated female rape and aggravated assault victims', and male aggravated assault victims' experiences of police interviews in Sweden, and the victims' inclinations to narrate about the crime events. A majority of the victims experienced their interviews as very calm, with very obliging, co-operative, helpful, and friendly interviewers. Such attitudes indicate a positive demeanour on the part of police officers and an understanding of the crime victims' situation (Stephens \& Sinden, 2000).

The humanitarian interviewing style and crime victims' responses of being respected and co-operative were found to be related to providing information in their narratives. The humanitarian interviewing attitude is consistent with previous research supporting the establishment of rapport to gather information from crime victims (see Fisher \& Geiselman, 1992; Milne \& Bull, 1999; Shepherd, 1991; Shepherd \& Milne, 1999; Shepherd et al., 1999). A humanitarian interviewing style is also in line with the therapeutic jurisprudential approach aiming to facilitate crime victims' psychological well-being, and as such, may be a first step in a healing process (Wexler, 2000; Winick, 2000). On the other hand, when the crime victims experienced a dominant interviewing style and responses of anxiety, it was found to be related to the victims consciously omitting information in the police interview. The experience of a dominant interviewing style may cause crime victims very high psychological costs, which Doerner and Lab (1998) suggested could further lead to investigation avoidance. Thus, interviewing styles may affect both the outcomes of a criminal investigation and a crime victim's healing process. Similar to Study 1, the experience of a certain interviewing approach may be a direct result of the interviewer's behaviour. It may also be a result of an interviewee's initial behaviour to which the interviewer responds, and which is subsequently experienced by the interviewee.

In sum, the present study shows that each crime victim was interviewed only once or twice per investigation, that these interviews were generally calm 
and that police interviewers were mainly seen as obliging, co-operative and helpful. Moreover, the crime victims' omission of information is more common when an interview is marked by a dominant style. On the other hand, a humanitarian interviewing style, feelings of being respected and cooperativeness are related to crime victims providing all information from painful crime events, and being more inclined to participate in crime investigations.

\section{Study 3}

Holmberg, U., Christianson, S-Å. \& Karlsson, I. Stressful Event Exposure is Related to Police Officers' Attitudes towards Interviewing Crime Victims and Suspects. Manuscript submitted for publication.

\section{Purpose}

Study 3 explored special squad police officers' attitudes towards conducting interviews concerning homicide, aggravated assault and sexual assault events with crime victims and suspects. In line with Study 1 and Study 2, this study examined whether police officers have attitudes congruent with a dominant or a humanitarian interview approach. This research also investigated officers' experiences of stressful events during their entire police career, as well as their reactions and coping mechanisms. A specific question was whether possible secondary or vicarious traumatization from work-related events accumulates over time and affects the investigator's attitudes in interviewing victims and suspects regarding violent and sexual crimes.

\section{Method}

Four hundred and thirty Swedish special squad police officers (response rate $81 \%, 112$ women and 318 men) completed a written interview. Mean age was 48.31 years with a range of $28-63$ years. Mean length of service was 26.04 years with a range of $5-41$ years. The police officers were randomly divided into two independent groups. One group was asked questions regarding interviewing crime victims and the other regarding interviewing suspects of homicide, aggravated assault, and sexual assault. The officers were asked to fill out items according to their attitudes in interviewing victims and suspects, respectively. The questionnaires were similar to those used in Study 1 and Study 2 focused on suspects' and crime victims' experiences of police interviews, but were changed to suit police officers as respondents (see Table 1-3 in Study 3). In Study 1 and Study 2, one item was formulated as follows, "To what extent did your interviewer act with calmness and give you time to comment?" The corresponding question in this study was changed to, "Some interviewers act with calmness and give the interviewee time to comment. To what extent do you act 
with calmness?" Apart from the questions about the police interview, the officers were also asked to describe in their own words the most emotionally stressful event experienced during their entire police career. The officers' descriptions were categorized into acts and events, criminal and non-criminal cases (see Table 4 and 5 in Study 3). The officers were also asked to rate the experienced psychological stress degree on a seven-point Likert scale. The questionnaire also comprised yes-or-no questions regarding psychological reactions; questions previously used by Karlsson and Christianson (2003). Moreover, based on previous research of Dyregov and Mitchell (1992), the officers were asked to report their coping mechanisms related to their reported emotional events.

\section{Major results}

The police officers' attitudes towards conducting interviews differ as a function of whom they have to interview. Principal component analysis with varimax rotation (PCA) conducted on the responses to the questionnaire revealed three attitudinal perspectives on interviewing crime victims (Table 1 in Study 3). The first factor revealed a perspective of humanity characterized by (in decreasing loading order) cooperativeness, helpfulness, accommodation, positive attitude, empathy, and a personal interest. Loadings of deprecation, aggression, rushing and a negative loading of calmness construe the second factor, affective dominance. A third factor, in the perspective of interviewing crime victims, was characterized by refusing dominance and comprised only two loadings, nonchalance and a brusque and obstinate demeanour. With respect to interviewing suspects, PCA revealed also three, but somewhat different, factors (Table 2 in Study 3). The first factor, humanity, comprises the same loadings as in the attitude towards interviewing crime victims, but in a different decreasing loading order (cooperativeness, helpfulness, positive attitude, personal interest, accommodation, and empathy). The second factor, dominance, is characterized by nonchalance, impatience, deprecations, unfriendliness and a brusque, and obstinate view (decreasing loading order). Calmness, a negative loading of aggression and a positive loading of friendliness construed the third factor, kindness.

Ninety percent of the 430 police officers in this study reported that they, at least once during their career, had experienced very emotionally stressful events. Fifteen of these officers were unable to pick out and describe the single most stressful event among their experiences, and they answered the other questions with one or more event in mind. A total of 372 police officers described a single stressful event they had experienced and rated the psychological stress experienced from the event. The most frequent category of stressful events reported by police officers on patrol duties were accidents with fatal outcomes (e.g., traffic accidents), and different kinds of intervention, for example actions against armed dangerous people and mentally disordered people. The risk of contracting a human immunodeficiency virus infection (HIV) was the exposure was reported as the highest stress degree and chasing/searching a suspect (i.e., a suspect armed with a gun) was the second most stressful event in patrol duty. Regarding 
investigative duties, the most frequent category of stressful events reported was experienced when officers worked in a homicide investigation team and investigated, for example, child homicide or the killing of a police officer. The highest stress degree experienced, reported from investigative duties, was exposure as single-handed investigators of child homicide or sexual abuse and interviewing abused and maltreated children (i.e., sexually abused or assaulted children). Depressive symptoms, feelings of sadness and fits of crying, insomnia, and body tensed up were the most common reactions reported by the police officers after being exposed to stressful events. Feelings of sadness and fits of crying were significantly more frequently reported from experiences related to investigative duty (42\%) compared with experiences related to patrol duty. The most frequent coping mechanisms the officers used to manage stressful situations were maintaining contact with fellow workers, mental preparation, using humour, and thinking practically.

Correlation analyses of police officers' reaction to stressful events and the officers' attitudes towards interviewing crime victims showed that depressive feelings were significantly related to the PCA factor humanity in interviewing crime victims, and its underlying variables friendliness and deprecations. A similar association was revealed between feelings of bad conscience, self-blame, and sadness and the humanitarian approach towards crime victims. In the perspective of interviewing crime victims, overreactions to sudden sound and movements related significantly to the PCA factor affective dominance.

Post-event reactions such as suffering from insomnia, depressive feelings, sadness and fits of crying and withdrawals from other people correlated significantly with a rushing interviewing attitude regarding interviews with suspects. Analyses also revealed that depressive feelings related inversely to being helpful in a suspect interview. Likewise, sudden mood fluctuation as well as tendency to withdraw from other people correlated negatively and significantly with a helpful attitude towards interviews with suspects. Feelings of bad conscience, selfblame, and guilt were also found to be inversely related to an aggressive attitude towards interviewing suspects, whereas nightmares after stressful events were significantly and positively correlated with personalizing the suspect interview.

The coping mechanism that appeared to be most prominent in its relation to aspects of interviewing crime victims was mental preparation, which was inversely associated with the PCA factor refusing dominance. Mental preparation was also inversely related to unfriendliness and positively correlated with calmness. In interviewing suspects, mental preparation related to a brusque view, shutting out thoughts and feelings was negatively correlated to empathy, and thinking practically related inversely to a nonchalant view. Experiencing the event as unreal correlated with a rushing approach, concentration on the task was related to aggressiveness, and shielding oneself from unnecessary impressions correlated with deprecations. 


\section{Conclusion}

Study 3 demonstrated that special squad police officers in Sweden have somewhat different attitudes towards interviewing crime victims and suspects, which is in line with previous research concerning the attitudes crime victims and suspects have perceived (see Study 1 and Study 2). Regarding crime victims, the more distinct humanitarian style is in line with Stephens and Sinden's (2000) findings, where victims of domestic violence perceived the officers as attentive, concerned, listening, emphatic, helpful, and respectful.

Police officers' dominant approach is interpreted by crime victims as mistrust and negativity (see Stephens \& Sinden, 2000). The dominant approach towards suspects mirrors the coercive and confrontational behaviour that several researchers have interpreted as having negative consequences for the outcome of police interviews (see, e.g., Leo, 1992; Moston \& Engelberg, 1993; Moston \& Stephenson, 1993). These results indicate an inclination to exert external pressure on suspects, perhaps in a confession-seeking manner, or interviewers are unaware of the mechanisms and prerequisites underlying traumatized victims' and suspects' possibilities to provide information. Such mechanisms and prerequisites are related to psychological distress and memory performance. For example, memories from emotional experiences are retained to a higher degree than are those from neutral experiences (see, e.g., Christianson, 1992a). An alternative assumption may be that some police officers are inclined to avoid closer contact with suffering or objectionable people in order to avoid secondary or vicarious traumatization (see e.g., Croft, 1995; Pearlman \& Mac Ian, 1993).

In line with other reports about stress and trauma in police work (e.g., Herrman, 1989; Karlsson \& Christianson, 2003; Mitchell-Gibbs, \& Joseph, 1996), the present study indicates that Swedish special squad police officers experience highly stressful events in their work. Exposures to stressful events in the police work cause high stress, but there may be a difference regarding how to cope with the stress. In patrol duty, the police officers are often ordered (via communication radio) to go to a certain place and execute certain legal procedures, which sometimes may be very stressful, but probably limited in time. In investigative duty, an officer often knows in advance when he or she will be entering a stressful situation, and may be aware that his or her behaviour can critically affect the outcome of the officer's achievement. The interviewer, who implicitly or explicitly shows, for example, deprecations in the interview, could be interpreted as mistrusting by the interviewee. Such an interpretation may be experienced as a high cost, which Doerner and Lab (1998) described as counterproductive to the investigation.

An important issue addressed in the current study was to what extent secondary or vicarious traumatizations from cumulated trauma-related events (cf. Pearlman \& Mac Ian, 1993) influence the investigator's attitudes towards interviewing victims and suspects. Results show that symptoms from stressful event exposure and subsequent coping mechanisms are related to police officers' re- 
ported negative attitudes towards interviewing suspects and supportive attitudes towards crime victim interviews.

In conclusion, the present study shows that an overwhelming majority of the special squad police officers have perceived, during their entire career, high stress due to exposure to different events in patrol or/and investigative duty. Reactions from such exposures have serious negative impacts on the police officers' psychological well-being, but may also affect the interviewing approach they adopt and exhibit in interviews with crime victims and suspects.

\section{GENERAL DISCUSSION}

\section{The main findings and further considerations}

The overall findings show that police interviews with suspects as well as crime victims in Sweden are perceived as either being marked by a dominant or a humanitarian approach. This study explores suspects' as well as crime victims' experiences of being interviewed, and how these experiences are related to interview outcomes. Findings from interviews with murderers and sexual offenders show that interviews characterized by humanity are significantly related to suspects admitting crimes, while the dominant approach shows a weak association with suspects denying crimes. The experiences of a humanitarian approach by female victims of rape, female and male victims of aggravated assault correlate significantly with these crime victims providing all information they can remember during their interview. These crime victims' experiences of a dominant interviewing approach are significantly related to crime victims omitting information during the police interview. Special squad police officers' attitudes towards conducting interviews with these suspects and crime victims are characterized principally by humanitarian and dominant interviewing attitudes. Moreover, an overwhelming majority of these police officers have, at least once during their career, been exposed to a very stressful event. Reactions from such exposures negatively influence attitudes towards interviewing suspects, but positively influence attitudes towards interviewing crime victims.

The dominant police interview approach is in line with perspectives derived from the first half of the past century, whereas the humanitarian interviewing style is congruent with the modern era of police interviewing. How the experience of a dominant or a humanitarian approach is created may vary. The interviewee's interpretation of a certain approach may have a direct causal relationship on the behaviour of the interviewer and the experiencing interviewee. It may also be caused by an interviewee's behaviour, which leads to certain responses in the interviewer, which are in turn perceived by the interviewee. The humanitarian interview attitudes, found in the present studies, are congruent with interview methods suggested during the most recent part of the past century. Early forerunners such as Leche and Hagelberg (1945) and Gerbert (1954) together with modern researchers (e.g., Fisher \& Geiselman, 1992; Fisher, 1995; 
Shepherd 1991, 1993; Shepherd et al., 1999; Yuille et al., 1999; Williamson, 1993) have emphasized the importance of showing open-mindedness, understanding, empathy, and establishing rapport in the police interview. The humanitarian interview approach is in line with what modern researchers suggest as the most valid and reliable method of gathering information from crime victims and suspects. Moreover, it is reasonable to assume that the experience of a humanitarian approach generates a mental space wherein suspects can narrate and admit the crime (Study 1) and crime victims can provide all information from the crime event (Study 2). The dominant interview attitude related to suspects' denials (Study 1) and crime victims' omissions (Study 2) may be reminiscent of the early decades of the past century, and as such, an expression of lacking or defective training. Without training, police officers create their own interview methods by learning on the job or by observing senior colleagues (Fisher \& Geiselman, 1992). Such methods, termed as the standard method, are often marked by frequent questioning (see, e.g., Clifford \& George, 1996). The dominant interviewing style is still in practice, and may be seen as synonymous with the standard method signified by frequent questioning, rushing and no time for reflection, in some sense congruent with the inquisitorial questioning suggested by Hassler (1930). Moreover, Leo (1996) observed 153 interviews with suspects and found that police officers (85\%) typically began the interview by confronting the suspect with existing evidence of his/her guilt. Such procedures may be seen as consistent with the dominant approach found in the present study.

In the 1960s, Inbau et al. (1962/1986) developed a persuasive police interview technique that received overwhelming critique. Persuasive techniques cause resistance in the interview, but its confession-seeking and deceptive nature may even generate false confessions (see, e.g., Gudjonsson, 1992, 2003; Moston \& Stephenson, 1993; Zimbardo, 1967). Persuasive techniques were not within the scope of this thesis. However, one may speculate whether the humanitarian approach, with its rapport-establishing feature, could be used as a deceptive procedure, although this notion is contradicted by the significant relationship between the humanitarian approach and suspects' reactions of feeling respected.

\section{The role of attitudes in police interviews}

In line with a study by Cherryman and Bull (2001), Study 3 showed that empathy was the second lowest and the lowest loadings of the principal component analyses regarding police officers' attitudes towards interviewing crime victims and suspects, respectively. Empathy, personal interest in conversation, positivity, cooperativeness, helpfulness, obliging manner and friendliness are such humanitarian attitudinal incentives, which are congruent with what most researchers emphasize as important in interviewing people (see, e.g. Bull, 2000; Fisher \& Geiselman, 1992; Fisher, 1995; Milne \& Bull, 1999, 2003; Shepherd, 1991, 1993; Shepherd \& Milne, 1999; Shepherd et al., 1999; Williamson, 1993; Yuille et al., 1999). However, although empathy is stressed as most important by researchers, police officers do not evaluate it as highly. 
Attitudes, values and beliefs are mediating factors that influence communication (Hargie \& Tourish, 2000). Attitudes are defined by Eagly and Chaiken (1998) as a psychological tendency to evaluate and express a positive or a negative value with regard to a certain attitude object. Thus, the valuations that follow the individuals into a police interview and the evaluations conducted during the interview are attitudes that will be expressed as approval or disapproval, approach or avoidance. The humanitarian police interview and feelings of being respected are related to approval and approaching behaviour, whereas the dominant style and anxious feelings are more associated with disapproval and avoidance. The dominant style is in line with the findings of Sear and Stephenson's (1997) study, which showed police officers as cold, calculating and dominant towards others. The Sear and Stephenson study also revealed that personality openness was a major component of interviewing efficacy, and the humanitarian approach indicates such a personality trait. The police interviewer's presumption of a suspect's guilt may cause behavioural confirmation by an attitudinal approach expressed through pressure and dominance (Kassin, 2003). In such conditions, Kassin found that suspects became more defensive.

The attitude objects in the police interview can be represented by the parties of the interview, but also by the interview itself. This implies that the evaluative responses an interviewer or an interviewee perceives may emanate from previous experiences (e.g., a prior encounter with the police), or as a direct response during the interview. Moreover, the availability of an attitude depends on how it has been structurally remembered, and its accessibility depends on its readiness at a specific time. Attitude strength refers to how an attitude persists over time and situations. Perceptions of a dominant approach may be explained by a first encounter with a police officer who displayed mistrust and an impatient demeanour (Shoham, 2000; Stephens \& Sinden, 2000). It may also be explained by a lack of humanitarian incentives during the interview. Thus, an evaluative response of being treated with humanity or dominance may be caused by the interviewer's behaviour. On the other hand, it can also be explained by behaviour of the interviewee that is mirrored by the interviewer and subsequently evaluated by the interviewee. The next section will discuss how an attitudinal interviewing style may change due to attitudinal evaluations of the individual.

\section{Attitude functions in police interviews}

Ninety percent of the police officers in Study 3 reported that they had been exposed to extremely stressful events during their entire career. Study 3 does not specifically investigate this stress, but instead its consequences for interviewing people, expressed through different attitudes. Attitudes function such that positive attitudes serve as an approaching function and negative attitudes serve to generate avoidance (Chen \& Bargh, 1999). Reactions from such experiences may generate avoidances of internal (e.g., awaken traumatic memories) or external (e.g. an interviewee who narrates about very painful experiences) realities. 
The generated avoidance can be explained by an ego-defensive function of attitudes (Katz, 1960), which in its turn is expressed through a dominant interview approach. Croft (1995) assumed that police interviewers' reluctance to use the phase of context reinstatement in the CI may be based on an unwillingness to watch and listen to a female rape victim re-experiencing the rape. Somewhat speculatively, it may be that to protect themselves from the pain and anxiety of causing the women additional pain, an ego-defensive function is triggered in the officers, which causes them to avoid use of the context re-establishing phase in the CI. It also seems reasonable to assume that very stressful experiences that generate ego-defensive functions may explain why some interview-trained officers return to previous interviewing behaviours. This retrogression, which Clarke and Milne (2003) found indications of, may be explained by an attitudinal ego-defensive function that hinders implementation of a trained interviewing technique.

Dominant interviewing attitudes that are evaluated as counter-attitudinal by a highly ego-involved character are perceived as threatening (Lapinski \& Boster, 2001). It is understandable that crime victims, suspects and police officers, who have been exposed to or involved in highly stressful events, are affected by stress reaction processes (Huether et al., 1999). In Study 3, police officers reported experiences from stressful event exposures during patrol duty that are in line with findings from previous studies (see, e.g. Anderson et al., 2002; Anshel et al., 1997; Brysiewicz, 2002; Salston \& Figley, 2003). Study 3 brings up one aspect that has not been salient in previous research; that is, stressful exposures also occur in investigative duty. Different stressors from extensive and frequent work with sexual offenders may cause a compounded stress (Lea et al., 1999). When stressed, the officer experiences an imbalance between his or her resources to cope with the situation and the demands the officer perceives, which in turn causes a stress reaction process (Carlier et al., 1997; Classen \& Koopman, 1993; Goldberger \& Breznitz, 1993; Huether et al., 1999). Stress reactions as, for example, depressive symptoms and feelings of sadness and fits of crying, reported in Study 3, are congruent with findings from previous studies and may cause vicarious traumatizations (see, e.g., Hallett, 1996; Herrman, 1989; Karlsson \& Christianson, 2003; Mitchell-Gibbs \& Joseph, 1996; Saakvitne \& Pearlman, 1996). Debriefing could be a way of working through stressful experiences. Unfortunately, few officers in Study 3 had been offered debriefing, and in such conditions police officers are left to find their own ways of working through their feelings. The police officers coping mechanisms, such as maintaining contact with fellow workers, mental preparation, and thinking practically, as reported in Study 3, indicate a problem-oriented coping strategy that is congruent with findings from previous research (Kenny, 200b; Karlsson \& Christianson, 2003; Stephens et al., 1997). Talks with colleagues were rated as most helpful in Study 3, which is in contrast to previous research showing that police officers rarely discuss their emotions with anyone (Pogrebin \& Poole, 1995). However, this is not necessarily contradictory, because Study 3 does not 
reveal whether the officers actually talk about emotional issues, but nevertheless that they found talking with colleagues very helpful. Stress reactions and coping mechanisms and subsequent attitudes may, through an ego-defensive function, automatically influence the behaviour of the parties of the police interview.

The instrumental or utilitarian function (Katz, 1960) may explain the behaviour of a police officer who shows a humanitarian attitude for practical reasons. In line with such a perspective, Demski and McGlynn (1999) demonstrated that parole officers' attitudinal beliefs towards parolees were associated with the instrumental or utilitarian function. The value-expressive function (Katz, 1960) may explain the behaviour of the officer who performs humanitarian, "fruitbearing" interviews for his or her own satisfaction with being a talented police interviewer. If this police officer were not striving for his or her own satisfaction, but instead for improvement of his or her knowledge to expand a constructive skill in order to better face and manage a humanitarian approach, this would be explained by the knowledge function (Katz, 1960). Thus and somewhat speculatively, a humanitarian interview attitude towards crime victims and suspects can be explained using the instrumental, value-expressive or knowledge functions, and the dominant approach using the ego-defensive function.

\section{Attitude automaticity in police interviews}

Wegner and Bargh (1998) described two attitudinal automatic processes whereof the first comprises an initial analysis of the environment that manages attentional screening. The second process comprises efficient attentional and behavioural skills that are initiated consciously and attentionally. Unintentional influences on perceptions may occur outside awareness, and efficient parallel processes can be executed by the individual's conscious will. Thus, attitude activation may occur automatically, and depending on its automaticity, may more consistently influence behaviour than would a controlled conscious process. This means that the parties in a police interview initially analyse each other and whatever they are able to perceive (e.g. humanity or dominance), and that attentional screening automatically influences the individuals' evaluations. An interviewee or an interviewer who perceives a humanitarian or forthcoming approach may automatically evaluate the situation as positive. That, in turn, may automatically trigger feelings of being respected and co-operative, which in turn may generate automatic behaviour of further developing a humanitarian approach. Subsequently and in a forthcoming interaction, the interviewee may provide all available information in the police interview. On the other hand and in the dominant perspective an ego-defensive function of the interviewee or the interviewer may be automatically activated. Such activation may be based on previous stressful experiences or a direct negative evaluation of the interview in progress. According to the research of Todorov and Bargh (1999), attitudes characterized by impatience, rushing, nonchalance, unfriendliness, deprecations and aggressiveness, which construe the dominant interview style in this study, constitute the type of environmental stimuli that automatically affect a person's attentional screening. 
Such screening as well as environmentally induced behaviour may automatically generate aggression and hostility (Todorov \& Bargh, 1999). For the police officer who has the mandate to conduct a professional interview, one way to avoid such activation may be to ask himself or herself about the attitudes he or she has towards these interviewees. Extensive previous research has shown that victims of aggravated assault and rape may develop ASD and PTSD (see, e.g., Dahl, 1992; Davis et al., 1997; Doerner \& Lab, 1998; Gore-Felton et al., 1993; Kilpatrick et al., 1998; Norris \& Feldman-Summers, 1981; Pynoos et al., 1993; Renk, 1997; Shoham, 2000). Even perpetrators of serious crimes of violence and sexual assaults show symptoms of psychological distress related to the criminal act (see, e.g., Adler et al., 2001; Blackburn, 1993; Cartwright, 2001; Dutton, 1999; Gudjonsson, 1992, 2003; Pollock, 1999). It is likely that these stressful experiences and sufferings unconsciously affect the individual's formation of attitudes that follow the individual into the police interview. It is also reasonable to assume that even police officers' experiences influence their attitude formation.

This study has shown that almost all special squad police officers have been exposed to very stressful events in their police work. Conducting police interviews may be one such working situation. Reactions and coping mechanisms may affect the police interviewers' attitudes and activate automatic egodefensive functions. Results show that symptoms from stressful event exposures and its coping mechanisms are correlated with negative attitudes towards interviewing suspects and with supportive attitudes towards crime victim interviews. To cope better with such stressful experiences, police officers need the opportunity to work through them, after which police officers may improve their ability to use conscious closed-loop control processes to handle stressful interview situations.

With an understanding of one's own attitudes, it is likely that they can be changed. It is important that this kind of introspection be done from time to time, and before entering an interview, otherwise the Cognitive Monster (Bargh, 1999) may activate the dominant approach. The Cognitive Monster is Bargh's metaphor describing the negative functions of prejudices and attitudes that are executed automatically. All automatic processes are conditional and appear in a variety of forms related to the specific environment or condition (Wittenbrink et al., 2001), which explains the effects of the dominant as well as the humanitarian approach. During an interview, and depending on the expressed behaviour, attitude formation may take place automatically (Wegner \& Bargh, 1998). Thus, an initial perception of a humanitarian approach may automatically change to a view of dominance if the individual, in his or her attentional screening of the environment, perceives negative stimuli. A change in the other direction is more difficult, because the mere exposure to such an attitude increases the respondent's defensiveness, which is counterproductive to building rapport (La France \& Boster, 2001). 
Researchers have emphasized the importance of rapport building in police interviews (see, e.g., Fisher \& Geiselman, 1992; Kebbell, Milne \& Wagstaff, 1999; Milne \& Bull, 1999, 2003; Shepherd, 1991; Shepherd \& Milne, 1999; Shepherd et al., 1999). Contrary to what researchers suggest, Pearse and Gudjonsson (1996) observed 161 recorded police interviews with suspects and found an initial rapport building process in only $3 \%$ of these interviews. Nevertheless, a humanitarian interviewing style promotes rapport building through its underlying notions of empathy and a personalizing approach, which Fisher and Geiselman (1992) stressed as rapport facilitating. Ridgeway (2000) argued that rapport is built on ethical parameters, the humanitarian style - with its empathy, personalization, positivity, helpfulness and accommodating approach - mirroring such ethical parameters. Moreover, Tickle-Degnen and Rosenthal (1990) described rapport as prototypical components comprising attentiveness, positivity and coordination. Hendrick (1990) viewed these components as feelings of mutual interest and focus (attention), feelings of friendliness and warmth (positivity), balance and harmony (coordination). The humanitarian interviewing style in the present thesis suggests the advantages of operationalizing rapport from an insider perspective. Showing personal interest, creating personal conversation and being helpful in the humanitarian interviewing style mirrors the feelings of interest and focus in the attention component of rapport (cf. the quotation on p. 4). Friendliness and warmth in the rapport component positivity are in line with positive attitude and empathy in the humanitarian interviewing style. The coordination component of rapport, with feelings of balance and harmony, is in line with cooperative and accommodating behaviour in the humanitarian interviewing approach. Cooperation needs balance, otherwise communication in the interview will be more one-way, and harmony presupposes a certain amount of accommodating behaviour. Thus, the humanitarian interviewing style offers, from an insider perspective, an operationalization of rapport as an intrinsic interactional phenomenon with mutual feelings that, according to Tickle-Degnen and Rosenthal, distinguish rapport from other constructs (e.g., empathy).

The humanitarian interview attitude promotes rapport, and may automatically serve as an instrumental or adjustment function in that sense that the interviewee provides all available information in the interview, which is supported by the research of Collins et al. (2002) and Butler et al. (2003). Additionally, Benneworth (2003) demonstrated, in line with a humanitarian approach, that a police officer who surrenders the floor by using open-ended questions about relationships and assists the suspect in recreating an emotional history facilitates admission. Such an approach enhances the individual's prospects for rehabilitation and psychological well-being, in line with the therapeutic jurisprudential practice (Petrucci et al., 2003; Wexler, 1996a, 1996b, 2000; Winick, 2000). In fact, already in 1908, Roscoe Pound, a Harvard jurist, criticized the existing jurisprudence, which he called mechanical jurisprudence (MJ), and he argued that the 
law functioned as an autonomous discipline (Finkelman \& Grisso, 1996). Pound proclaimed that MJ "lived" its own sovereign life and that the consequences of a crime were only seen in legal terms, which in turn led to the development of sociological jurisprudence (Dow, 2000; Finkelman \& Grisso, 1996). In the late 1980 s and based on the mental health law, therapeutic jurisprudence (TJ) began to grow in the US and in this perspective the law and the execution of legal procedures are seen in the context of the behavioural sciences (Petrucci et al., 2003). The law, the execution of the law though different procedures and legal actors can function as therapeutic agents because the law and its execution often generate therapeutic or anti-therapeutic consequences (Petrucci et al., 2003). TJ calls for the acceptance of legal doctrines and procedures that are based on knowledge of mental health and psychological theories (Wexler, 1996a). In the scope of TJ, the application of legal rules and procedures, in line with the humanitarian approach, is performed to promote the physiological and psychological well-being of the individual involved in the juridical action (Wexler, 1996b). For example, certain attitudes of legal actors in legal actions may, according to the TJ approach, facilitate or undermine crime victims' and suspects' psychological well-being and may be a first step in a healing process (Petrucci et al., 2003; Wexler, 2000; Winick, 2000). The dominant style, as an anti-therapeutic approach, may hinder an interviewee's possibility of recreating the context of an event, which would facilitate the recollection of the event in focus (see, e.g., Baddeley, 1998; Fisher \& Geiselman, 1992; Fisher, 1995; Christianson, 1992a). Soukara, Bull and Vrij (2002) examined 40 experienced detectives' perspective on interviewing uncooperative suspects and found that $80 \%$ of the officers rated social skills as very important prerequisites of successful interviews. An antitherapeutic dominant approach may indicate a lack in social skills whereas a therapeutic jurisprudential and humanitarian approach may be consistent with social skills.

\section{Words of caution}

This thesis rests on retrospective data collected via self-reports, and of course it has its limitations and may be somewhat biased by different memory effects. For example, anxiety-related memories are marked by more negative tone in comparison with content memories, and individuals with high self-esteem recall memories with greater positivity than do individuals with low self-esteem (Setliff \& Marmurek, 2002; Wenzel, Pinna \& Rubin, 2004). Moreover, negative emotional events are very well remembered regarding the event itself and central detail information, and negative events are more easily accessible than pleasant events (Christianson, 1992b; Mark, \& Williams, 1992). Regarding memory effects, it is necessary to realize that these data mirror real-life events that have likely awoken emotions that may have enhanced memories (Christianson, 1992c). Such memories cannot be seen as equal to memories from laboratory studies where it is impossible and illegal to create situations comparable with the experiences dealt with here. Individual characteristics and experiences from the 
events in focus may have had an effect when suspects, crime victims and police officers have completed the questionnaire. For example, an interviewee who has experienced dominant interview attitudes may have shown a somewhat more negative adjustment in participating in this study compared to an interviewee who has perceived humanitarian attitudes. Likewise, those who have perceived humanitarian attitudes may have shown a somewhat positive bias in their responses. Effects like these are hard to control in a retrospective study like the present one. Nevertheless, these memory effects may exist.

In rating interviewing attitudes, police officers rated their own attitudes whereas crime victims and suspects rated their perceptions of police officers' attitudes. Thus, social desirability may have had more influence on the police officers (Study 3) than on the crime victims (Study 2) and suspects (Study 1).

Regarding response frequency, it was quite low for crime victims and perpetrators, which may be a weakness for the two first studies. Nevertheless, the groups were large enough to explore different experiences of the police interview. The response rate for police officers was quite high and caused no problems.

In the investigation of police officers' stress, a standardized stress inventory was not used, because such instruments have been criticized for comprising implicit associations not clearly established by research (Jones \& Bright, 2001). Instead, the police officers described their stressful experiences in response to an open-ended question.

The results show crime victims', offenders', and police officers' subjective experiences of the police interview, which do not necessarily mirror what actually happened during the interview. However, there are few real-life studies that present the voices of the parties in the police interview and that show, from their point of view, what factors affect their behaviour and decisions. The present study complements the important studies of recorded police interviews that British researchers have conducted (Baldwin, 1992, 1993; Clarke \& Milne, 2001, 2003; Moston \& Engelberg, 1993; Stephenson \& Moston, 1993). Additionally, it is important to investigate crime victims' and suspects' perceptions; otherwise we cannot know anything about their motives and thoughts when they provide or withhold information during police interviews. It is also important to investigate police officers' experiences of their work in order to find associations between experiences and behaviour. Otherwise we cannot know anything about why police officers do not do what they are recommended to do or about what they say they are going to do. The data in this thesis show a clear correlation between perceived interview attitudes and interview outcome, but cannot prove any causal relationships.

\section{Conclusions}

The present thesis focuses on police interviews regarding very serious crimes of violence and sexual offences. Results reveal crime victims', murderers' and sexual offenders' experiences of being interviewed and police officers' attitudes 
towards conducting interviews related to traumatizing crimes. The first study revealed that when police officers interviewed murderers and sexual offenders, the interviewees perceived attitudes characterized by either dominance or humanity. Police interviews marked by dominance are mainly associated with a higher proportion of denials, whereas an approach marked by humanity is associated with admissions. There was a strong tendency for sexual offenders to perceive themselves as being more insulted and condemned by police interviewers than murderers did. In line with Study 1, the crime victims in Study 2 also revealed the experience of two police interview styles, where an interviewing style marked by dominance was mainly associated with crime victims omitting information. On the other hand, a humanitarian interviewing style was related to crime victims providing all information from painful crime events. This means that the crime victims did not consciously omit any remembered information. When the crime victims perceived humanity, felt respected, and became cooperative, they were also likely to be more inclined to participate in crime investigations. Suspects' and crime victims' experiences of being treated with dominance or humanity may be an attitudinal evaluation of behaviour initiated by the interviewer. It may also be the interviewee's behaviour that is mirrored by the interviewer and subsequently evaluated by the interviewee. Police officers' attitudes towards interviewing crime victims also showed a humanitarian approach, but additionally two dominant approaches, one affective and the other refusing. The attitude towards interviewing suspects of the crimes in focus revealed humanitarian and dominant interviewing attitudes, and an approach marked by kindness.

The present thesis shows that, during their entire career, an overwhelming majority of the special squad police officers had experienced stressful events in patrol as well as investigative duty. Reactions from such exposure may have serious negative impacts on the police officers' psychological well-being, and may also affect the interviewing approach they adopt (Hallet, 1996; Iliffe, 2000; Lea et al., 1999). Results show that symptoms from stressful event exposures and subsequent coping mechanisms are associated with negative attitudes towards interviewing suspects and supportive attitudes towards crime victim interviews. Thus, experiences from stressful exposures may automatically activate ego-defensive functions that automatically generate dominant attitudes. Moreover, it is important to offer police officers who have been exposed to stressful events the opportunity to work through their experiences, for example, through structured debriefing procedures. After debriefings, police officers are better prepared to meet crime victims and suspects and to, through conscious closedloop processes, conduct police interviews without awakening ego-defensive functions. An additional consequence of debriefing may be to increase police officers' possibilities to improve their interviewing skills through training and to implement what they have learned. Use of the humanitarian interview may also enhance the possibilities for crime victims and suspects to provide investigative information. In such circumstances, crime victims', suspects' and police offi- 
cers' prospects for attaining psychological well-being and rehabilitation may increase.

\section{Future directions}

The studies in this thesis have laid the foundations for future research regarding several areas of police work, but first a recommendation. The term interrogation has been changed in Britain to investigative interviewing (Milne \& Bull, 2003), which seems to be a very wise step in changing attitudes towards the police interview. The term investigative interviewing indicates a dualistic, open-minded communication in line with a humanitarian approach, whereas interrogation denotes a more inquisitorial questioning style signifying a dominant approach. Such a change should be widely adopted in law enforcement and its analogue is likely applicable in most languages, not least in the Swedish language.

Second, given our knowledge of crime victims' and suspects' perceptions of police interviews and police officers' attitudes towards conducting interviews, it is most important to study what happens in real-life police interviews. For example, in a longitudinal quasi-experiment a researcher might investigate what factors affect the parties of the interview and what factors may facilitate improvements. Such a study might include, as Milne and Bull (2003) emphasized, the communicative aspects of the police interview, focusing not only on what facilitates improvements, but also on identifying factors that are counterproductive. For example, on the part of police officers, stress reactions and rigid perspectives adopted during a career may block implementation of newly learned techniques.

Concerning the stress-reaction processes of crime victims and suspects, and their perceived attitudes, it is important to investigate the prerequisites of a positive attitude change, as such a change could improve their prospects for rehabilitation and psychological well-being. By investigating crime victims' and suspects' experiences and analyses of their recorded interviews, it may be possible to identify factors that could promote a change from dominance to humanity.

Stressful exposures are closely related to police work, but as Study 3 revealed painful stress reactions that may affect working behaviour, it is important that police management take these reactions seriously and create opportunities for police officers to work through their experiences. It is also important to investigate the effects of debriefings and to understand whether stressful experiences hinder implementation of trained behaviour, for example, how to conduct a good police interview.

Finally, research on police interviews is multi-faceted and is related, among other things, to cognitive as well as social psychology. Legal procedures not only have juridical effects, but to the highest degree, also psychological effects. It is the author's hope that this thesis has moved our scientific knowledge of the police interview one step forward, and that this contribution may lead to improvement of the psychological well-being of all people involved. 


\section{REFERENCES}

Adler, F., Mueller, G. O. W. \& Laufer, W. S. (2001). Criminology. New York: McGraw-Hill.

American Psychiatric Association. (1994). Diagnostic and statistic manual of mental disorders, $4^{\text {th }} \mathrm{ed}$. Washington, DC: Author.

Anderson, G. S., Litzenberger, R. \& Plecas, D. (2002). Physical evidence of police officer stress. Policing: An International Journal of Police Strategies \& Management, 25(2), $399-420$.

Anshel, M. H., Robertson, M. \& Caputi, P. (1997). Sources of acute stress and their appraisals and reappraisals among Australian police as a function of previous experience. Journal of Occupational and Organizational Psychology, Vol. 70, pp. $337-356$.

Arther, R. O. (1955). Blood pressure rises on relevant questions in lie-detection - sometimes an indication of innocence not guilt. Journal of Criminal Law and Criminology, 46, pp. $112-115$.

Baddeley, A. (1998). Human memory; Theory and practice. Boston, Mass.: Allyn and Bacon.

Baldwin, J. (1992). Video taping police interviews with suspects - an evaluation (Police Research Series Paper 1). London: Home Office Police Department.

Baldwin, J. (1993). Police interview techniques; Establishing truth or proof? The British Journal of Criminology, Vol. 33, 3, pp. 325 - 352.

Bargh, J. A. (1999). The cognitive monster: A case against the controllability of automatic stereotype effects. In S. Chaiken \& Y. Trope (Eds.), Dual Process Theories in Social Psychology, (pp. 361 - 382). New York: Guilford Press.

Benneworth, K. (2003 July). Who 'tells the story' in the police-paedophile investigative interview and the encouragement of suspect denial. Paper presented at the Psychology \& Law International, Interdisciplinary Conference, Edinburgh, UK.

Blackburn, R. (1993). The psychology of criminal conduct: Theory, research and practice. Chichester: John Wiley \& Sons Ltd.

Brock, P., Fisher, R. P. \& Cutler, B. L., (1999). Examining the cognitive interview in a double-test paradigm. Psychology, Crime \& Law, 5, pp. 2945.

Brysiewicz, P. (2002). Violent death and the South African emergency nurse. International Journal of Nursing Studies, 39, 253 - 258.

Bull, R. (2000). Police investigative interviewing. In A. Memon \& R. Bull (Eds.) Handbook of the psychology of interviewing, (pp. 279 - 292). Chichester: John Wiley \& Sons Ltd. 
Butler, E. A., Egloff, B., Wilhelm, F. H., Smith, N. C., Ericson, E. A. \& Gross, J. J. (2003). The social consequences of expressive suppression. Emotion, Vol. 3 (1), pp. $48-67$.

Carlier, I. E. V., Lamberts, R. D. \& Gersons, B. P. R. (1997). Risk factors for posttraumatic stress symptomatology in police officers: A prospective analysis. The Journal of Nervous and Mental Disease, Vol. 185 (8), pp. $498-506$.

Cartwright, D. (2001). The role of psychopathology and personality in rage-type homicide; A review. South African Journal of Psychology, Vol. 31 (3), pp. $12-20$.

Chen, M. \& Bargh, J. A. (1999). consequences of automatic evaluation: Immediate behavioral predispositions to approach or avoid the stimulus. Personality and Social Psychology Bulletin, Vol. 25 (2), pp. 215 - 224.

Cherryman, J. \& Bull, R. (2001). Police officers' perceptions of specialist investigative skills. International Journal of Police Science and Management, Vol. 3 (3), pp. $199-212$.

Christianson, S-Å. (1992a). The handbook of emotion and memory: Research and theory. Hillsdale, NJ.: Lawrence Erlbaum Associates Publishers.

Christianson, S-Å. (1992b). Remembering emotional events: Potential mechanisms. In S-Å Christianson (Ed.), The handbook of emotion and memory: Research and theory (pp. 307 - 342). Hillsdale, NJ.: Lawrence Erlbaum Associates Publishers.

Christianson, S-Å. (1992c). Emotional stress and eyewitness memory; A critical review. Psychological Bulletin, 112 (2), pp. $284-309$.

Clarke, C. \& Milne, R. (2001). National evaluation of the PEACE investigative interviewing course. Home Office, UK, Police Research Award Scheme, Report No: PRSA/149.

Available: http://www.homeoffice.gov.uk/peace interviewcourse.pdf

Clarke, C. \& Milne, R. (2003 July). Interviews with victims and witnesses; The reality. Paper presented at the Psychology \& Law International, Interdisciplinary Conference, Edinburgh, UK.

Classen, C. \& Koopman, C. (1993). Trauma and dissociation. Bulletin of Menninger Clinic, Vol. 57(2), pp. $179-195$.

Classen, C., Koopman, C, Hales, R. \& Spiegel, D. (1998). Acute stress disorder as a predictor of posttraumatic symptoms. American Journal of Psychiatry, Vol. 155 (5), pp.620 - 624. (From PsycInfo, Abstract, AN: 1998-02306-007).

Clifford, B. R. \& George, R. (1996). A field evaluation of training in three methods of witness/victim investigative interviewing. Psychology, Crime \& Law, 2, pp. 231-248.

Collins, R., Lincoln, R. \& Frank, M. G. (2002). The effect of rapport in forensic interviewing. Psychiatry, Psychology and Law, Vol. 9 (1), pp. $69-78$.

Croft, S. (1995). Helping victims to remember. Police, November, 13 - 14. 
Dahl, S. (1992). Rape - a hazard to health. Oslo: Department of Psychiatry, University of Oslo.

Davis, R. C., Lurigio, A. J. \& Skogan, W. G. (1997). Victims of crime, $2^{\text {nd }}$ ed. London: Sage Publications.

Demski, R. M. \& McGlynn, R. P. (1999). Fear or moral indignation? Predicting attitudes towards parolees. Journal of Applied Social Psychology, Vol. 29, pp. $2024-2058$.

Doerner, W. G. \& Lab, S. P. (1998). Victimology. Cincinnati: Anderson Publishing Co.

Dow, D. R. (2000). The relevance of legal scholarship: Reflections on judge Kozinski's Musings. Houston Law Review, 37, pp. 329 - 340.

Dutton, D. G. (1999). Traumatic origins of intimate rage. Aggression and Violent Behavior, Vol. 4 (4), pp. $431-447$.

Dyregov, A \& Mitchell, J. T. (1992). Work with traumatized children: Psychological effects and coping strategies. Journal of Traumatic Stress, 5 (1), pp. $5-17$.

Eagly, A. H \& Chaiken, S. (1998). Attitude structure and function. In D. T. Gilbert, S. T Fiske \& G. Lindzey (Eds.) The handbook of social psychology, Vol. 2, (pp. 269 - 322). Boston: The McGraw-Hill Companies Inc.

Finkelman, D. \& Grisso, T. (1996). Therapeutic jurisprudence: From idea to application. In Law in a therapeutic key. Ed. Wexler, D. B. \& Winick, B. J. Durhamn, North Carolina: Carolina Academic Press.

Fisher, R. P. \& Geiselman, R. E. (1992). Memory-enhancing techniques for investigative interview; The cognitive interview. Springfield: Charles $\mathrm{C}$ Thomas Publishing.

Fisher, R. P. (1995). Interviewing victims and witnesses of crime. Psychology, Public Policy and Law, Vol. 1, 4, pp. $732-764$.

Gerbert, K. (1954). The psychology of expression and the technique of criminal interrogation. Jahrbuch fuer Psychologie undPsychotherapie, 2, pp. 85 -98 .

Gilbert, D. T. (1998). Ordinary personology. In D. T. Gilbert, S. T Fiske \& G. Lindzey (Eds.) The handbook of social psychology, Vol. 2, (pp. $89-$ 150). Boston: The McGraw-Hill Companies Inc.

Goldberger, L. \& Breznitz, S. (1993). Handbook of stress; Theoretical and clinical aspects, $2^{\text {nd }}$ ed. New York: The Free Press.

Gore-Felton, C., Gill, M., Koopman, C. \& Spiegel, D. (1999). A review of acute stress reactions among victims of violence: Implications for early intervention. Aggression and Violent Behavior, Vol. 4 (3), pp. 293 - 306.

Gudjonsson, G. H. (1992). The psychology of interrogations, confessions and testimony. Chichester: John Wiley and Sons.

Gudjonsson, G. H. (1994). Investigative interviewing: Recent developments and some fundamental issues. International Review of Psychiatry, Vol. 6, $2 / 3$, pp. $237-246$. 
Gudjonsson, G. H. (2003). The psychology of interrogations and confessions. New York: John Wiley and Sons Ltd.

Gudjonsson, G. H. \& Petursson, H. (1991). Custodial interrogation; Why do suspects confess and how does it relate to their crime, attitude and personality. Personality and Individual Differences, 12, 295 - 306.

Gudjonsson, G. H. \& Sigurdsson, J. F. (1999). The Gudjonsson QuestionnaireRevised (GCQ_R): factor structure and its relationship with personality. Personality and Individual Differences, 27, 953 - 968.

Hallett, S. J. (1996). Trauma and coping in homicide and child sexual abuse detectives. Dissertation abstracts international: Section, 57, 2152. Ann Arbor, MI: Bell \& Howell Company, University microfilms No. 9623716.

Hargie, O. \& Tourish, D. (2000). The psychology of interpersonal skill. In A. Memon \& R. Bull (Eds.) Handbook of the psychology of interviewing, (pp. $71-88$ ). Chichester: John Wiley \& Sons Ltd.

Hassler, Â. (1930). Föreläsningar över den Svenska kriminalprocessen, I. Stockholm: A.B. Nordiska Bokhandeln i Distribution.

Hendrick, C. (1990). The nature of rapport. Psychological Inquiry, 4, pp. 312315.

Herman, J. L. (2003). The mental health of crime victims: Impact on legal intervention. Journal of Traumatic Stress, Vol. 16 (2), pp. 159 - 166.

Herrman, J. D. (1989). Sudden death and the police officer. Issues in Comprehensive Pediatric Nursing, 12, 327-332.

Holmberg, U. (1994). Samtal med sexualbrottsoffer: Hur har kvinnorna upplevt kommunikationen med olika resurspersoner. Report series 1994:1. Kristianstad: Kristianstad University.

Holmberg, U. (1996). Sexualbrottsförövares upplevelser av polisförhör. Report series 1996:7. Kristianstad: Kristianstad University.

Holmberg, U. \& Christianson, S-Å. (2002). Murderers' and sexual offenders' experiences of police interviews and their inclination to admit or deny crimes. Behavioral Sciences and the Law, Vol. 20, pp. $31-45$.

Huether, G., Doering, S., Rüger, U., Rüther, E. \& Schüssler, G. (1999). The stress-reaction process and the adaptive modification and reorganization of neuronal networks. Psychiatry Research, 87, pp. 83 - 95.

Iliffe, G. (2000). Exploring the counsellors' experiences of working with perpetrators and survivors of domestic violence. Journal of Interpersonal Violence, Vol. 15 (4), pp. 393 - 413.

Inbau, F. E., Reid, J. E. \& Buckley, J. P. (1962/1986). Criminal interrogation and confession. Baltimore: Williams \& Wilkins.

Jones, F. \& Bright, J. (2001). Stress; Myths, theory and research. Harlov: Pearson Education Ltd.

Karlsson, I. \& Christianson, S- $\AA$. (2003). The phenomenology of traumatic experiences in police work. Policing: An International Journal of Police Strategies \& Management, Vol. 20 (3), pp. $419-438$. 
Kassin, S. M., Goldstein, C. C. \& Savitsky, K. (2003). Behavioral confirmation in the interrogation room: On the dangers of presuming guilt. Law and Human Behavior, Vol. 27 (2), pp. 187 - 203.

Katz, D. (1960). The functional approach to the study of attitudes. Public Opinion Quarterly, Vol. 24 (2), pp. 163 - 204.

Kebbell, M. R., Milne, R. \& Wagstaff, G. F. (1999). The cognitive interview: A survey of its forensic effectiveness. Psychology, Crime and Law, 5, pp. 101-115.

Kenny, D. T. (2000a). Psychological foundation of stress and coping: A developmental perspective. In D. T. Kenny, J. G. Carlson, F. J. McGuigan \& J. L Sheppard (Eds.), Stress and health: Research and clinical application (pp. 73 - 104). Amsterdam: Harwood Academic Publishers.

Kenny, D. T. (2000b). Occupational stress: Reflection on theory and practice. In D. T. Kenny, J. G. Carlson, F. J. McGuigan \& J. L Sheppard (Eds.), Stress and health: Research and clinical application (pp. 375 - 396). Amsterdam: Harwood Academic Publishers.

Kilpatrick, D. G., Resnick, H. S., Saunders, B. E. \& Best, C. L. (1998). Rape, other violence against women, and posttraumatic stress disorder. In B. P. Dohrenwend (Ed.), Adversity, stress, and psychopathology (pp. 161 - 176). New York: Oxford University Press.

Koppelaar, L., Lange, A. \& van de Velde, J-W. (1997). The influence of positive and negative victim credibility on the assessment of rape victims; An experimental study of expectancy - confirmation bias. International Review of Victimology, Vol. 5, pp. $61-85$.

La France, B. H. \& Boster, F. J. (2001). To match or mismatch? That is only one important question. Communication Monographs, Vol. 68 (3), pp. 211 $-234$.

Langfeldt, T. (1993). Sexologi. Oslo: Ad Notam Gyldendahl.

Lapinski, M. K. \& Boster, F. J. (2001). Modeling the ego-defensive function of attitudes. Communication Monographs, Vol. 68 (3), pp. $314-324$.

Lea, S., Auburn, T. \& Kibblewhite, K. (1999). Working with sex offenders: The perceptions and experiences of professionals and paraprofessionals. International Journal of Offender Therapy and Comparative Criminology, Vol., 43 (1), pp. $103-119$.

Leche, E. \& Hagelberg, V. (1945). Förhör i brottmål. Stockholm: P. A. Nordstedt \& Söners Förlag.

LeDoux, J. C. \& Hazelwood, R. R. (1985). Police attitudes and beliefs toward rape. Journal of Police Science and Administration, Vol. 13 (3), pp. $211-220$.

Leo, R. A. (1992). From coercion to deception; The changing nature of police interrogation in America. Crime, Law and Social Change, 18, pp. $35-$ 59.

Leo, R. A. (1996). Criminal law; Inside the interrogation room. The Journal of Criminal Law \& Criminology, Vol. 86 (2), pp. $266-303$. 
Mark, J. \& Williams, G. (1992). Autobiographical memory and emotional disorders. In S-Å Christianson (Ed.), The handbook of emotion and memory: Research and theory (pp. 451 - 477). Hillsdale, NJ.: Lawrence Erlbaum Associates Publishers.

Meijnders, A. L., Midden, C. J. H. \& Wilke, H. A. M. (2001). Role of negative emotion in communication about CO-sub-2 risks. Risk Analysis, Vol., 21 (5), pp. $955-966$.

Merriam-Webster Dictionary. (2004). Merriam-Webster OnLine. Available: http://www.m-w.com.

Milne, R. \& Bull, R. (1999). Investigative interviewing; Psychology and practice. Chichester: John Wiley \& Sons, Ltd.

Milne, R. \& Bull, R. (2003). Interviewing by the police. In D. Carson \& R. Bull (Eds.), Handbook of psychology in legal contexts, pp. $111-125$. Chichester: John Wiley \& Sons Ltd.

Mitchell-Gibbs, J. \& Joseph, S. (1996). Occupational trauma in the British police: Preliminary analysis. Issues in Criminological \& Legal Psychology, 25, 54-58.

Mortimer, A. \& Shepherd, E. (2000). Frames of mind: Schemata guiding cognition and conduct in the interviewing of suspected offenders. In A. Memon \& R. Bull (Eds.), Handbook of the psychology of interviewing (pp. 293 - 316). Chichester: John Wiley \& Sons Ltd.

Moston, S. \& Engelberg, T. (1993). Police questioning techniques in tape recorded interviews with criminal suspects. Policing and Society, Vol. 3, pp. $223-237$.

Moston, S. \& Stephenson, G. M. (1993). The changing face of police interrogation. Journal of Community \& Applied Social Psychology, Vol. 3, pp. $101-115$.

Münsterberg, H. (1908/1923). On the witness stand; Essays on psychology and crime. Classics in the history of psychology. An internet resource developed by Christopher D. Green (Ed.), York University, Toronto, Ontario.

Available:

http://psychclassics.yorku.ca/Munster/Witness/detection.htm.

Münsterberg, H. (1908/1925). On the witness stand; Essays on psychology and crime. Classics in the history of psychology. An internet resource developed by Christopher D. Green (Ed.), York University, Toronto, Ontario.

Available:

http://psychclassics.yorku.ca/Munster/Witness/confessions.htm.

Norris, J. \& Feldman-Summers, S. (1981). Factors related to the psychological impacts of rape on the victim. Journal of Abnormal Psychology, Vol. 90 (6), pp. $562-567$.

Patterson, M. L. (1990). On the construct validity and developmental course of rapport. Psychological Inquiry, 4, pp. 320-321. 
Pearlman, L.A., \& Mac Ian, P.S. (1993). Vicarious traumatization among trauma therapists: Empirical findings on self-care. Traumatic Stress Points: News for the International Society for Traumatic Stress Studies, 7 (3), 5 .

Pears, J. \& Gudjonsson, G. H. (1996). Police interviewing techniques at two south London police stations. Psychology, Crime \& Law, Vol. 3, pp. 63 $-74$.

Peixoto, A. (1934). The interrogation and confessions in the judiciary process. Revista de Criminologia Buenos Aires, 21, pp. 383 - 395.

Pennebaker, J. W. (1997). Opening up; The healing power of expressing emotions. New York: The Guilford Press.

Petrucci, C. J., Winick, B. J. \& Wexler, D. B. (2003). Therapeutic jurisprudence: An invitation to social scientists. In D. Carson \& R. Bull (Eds.), Handbook of psychology in legal contexts, (pp.579 - 601). Chichester: John Wiley \& Sons Ltd.

Pogrebin, M. R. \& Poole, E. D. (1995). Emotion management: A study of police response to tragic events. In Flaherty, Michael G. (Ed); Ellis, Carolyn (Ed). Social perspectives on emotion. Stamford, CT, US: JAI.

Pollock, P. H. (1999). When the killer suffers: Post-traumatic stress reaction following homicide. Legal and Criminology Psychology, 4, pp. $185-$ 202.

Pynoos, R. S., Sorenson, S. B. \& Steinberg, A. M. (1993). Interpersonal violence and traumatic stress reactions. In L. Goldberger \& S. Breznitz (Eds.), Handbook of stress: Theoretical and clinical aspects, $2^{\text {nd }}$ Ed., (pp. 573 - 590). New York: The Free Press.

Renk. B. (1997). Victim of crime in a public health perspective. Gothenburg: Nordic School of Public Health.

Reiser, M. \& Geiger, S. P. (1984). Police officer as victim. Professional Psychology Research and Practice, 15, 315-323.

Ressler, R. K., Burgess, A. W. \& Douglas, J. E. (1988). Sexual homicide; Patterns and motives. New York: Lexington Books.

Ridgeway, B. J. (2000). The hermeneutical aspects of rapport. Dissertation abstracts international section A: Humanities and social sciences, 2000 Feb., 60 (7-A), 2527. (University microfilms No. AEH9937686).

Saakvitne, K.W. \& Pearlman, L. A. (1996) Transforming the pain: A workbook on vicarious traumatization. A Norton professional book. New York, NY, US: W. W. Norton \& Co, Inc.

Salston, MD. \& Figley, C. R. (2003). Secondary traumatic stress effects of working with survivors of criminal victimization. Journal of Traumatic Stress, Vol. 16 (2), pp. $167-174$.

Sear, L. \& Stephenson, G. M. (1997). Interviewing skills and individual characteristics of police interrogators. Issues in Criminology and Legal Psychology, No. 29, pp. $27-34$. 
Setliff, A. E. \& Marmurek, H. H. C. (2002). The mood regulatory function of autobiographical recall is moderated by self-esteem. Personality and Individual Differences, Vol. 32, pp. $761-771$.

Shepherd, E. (1991). Ethical interviewing. Policing, Vol. 7, pp. $42-60$.

Shepherd, E. (1993). Resistance in interviews; The contribution of police perception and behaviour. Issues in Criminal and Legal Psychology, 18, pp. $5-12$.

Shepherd, E. \& Milne, R. (1999). Full and faithful: Ensuring quality practice and integrity of outcomes in witness interviews. In A. Heaton-Armstrong, E. Shepherd \& D. Wolchover (Eds.). Analysing witness testimony: A guide for legal practitioners and other professionals. London: Blackstone Press Limited.

Shepherd, E., Mortimer, A., Turner, V. \& Watson, J. (1999). Spaced cognitive interviewing: Facilitating therapeutic and forensic narration of trauma memories. Psychology, Crime \& Law, 5, pp. 117-143.

Shoham, E. (2000). The battered wife's perception of characteristics of her encounter with the police. International Journal of Offender Therapy and Comparative Criminology, 44 (2), pp. 242 - 257.

Soukara, S., Bull, R. \& Vrij, A. (2002). Police detectives' aims regarding their interviews with suspects: Any change at the turn of the millennium? International Journal of Police Science \& Management, Vol. 4 (2), pp. $100-114$.

Stephens, C., Long, N. \& Miller, I. (1997). The impact of trauma and social support on post traumatic stress disorder: A study of New Zealand police officers. Journal of Criminal Justice, 25 (4), 303 - 314.

Stephens, B. J. \& Sinden, P. G. (2000). Victims' voices; Domestic assault victims' perceptions of police demeanor. Journal of Interpersonal Violence, 15 , (5), $534-547$.

Stephenson, G. M. \& Moston, S. J. (1993). Attitudes and assumptions of police officers when questioning criminal suspects. Issues in Criminological and Legal Psychology, No. 18, pp. $30-36$.

Stephenson, G. M. \& Moston, S. J. (1994). Police interrogation. Psychology, Crime \& Law, Vol. 1, pp. $151-157$.

The Swedish Law, SFS 1974:203, § 25.

Tickle-Degnen, L. \& Rosenthal, R. (1990). The nature of rapport and its nonverbal correlates. Psychological Inquiry, 4, pp. 285-293.

Todorov, A. \& Bargh, J. A. (2002). Automatic sources of aggression. Aggression and Violent Behavior, Vol. 7 (1), pp. $53-68$.

Walther, E. (2002). Guilty by mere association: Evaluative conditioning and the spreading attitude effect. Journal of Personality and Social Psychology, Vol. 82 (6), pp.919 - 934.

Wegner, D. M. \& Bargh, J. A. (1998). Control and automaticity in social life. . In D. T. Gilbert, S. T. Fiske \& G. Lindzey (Eds.), The handbook of so- 
cial psychology, 4th ed. (pp. 446 - 496). Boston: Oxford University Press.

Wenzel, A., Pinna, K. \& Rubin, D. C. (2004). Autobiographical memories of anxiety-related experiences. Behaviour Research and Therapy, Vol. 42, pp. $329-341$.

Wexler, D. B (1996a). Therapeutic jurisprudence and changing conceptions of legal scholarship. In Law in a therapeutic key. Ed. Wexler, D. B. \& Winick, B. J. Durhamn, North Carolina: Carolina Academic Press.

Wexler, D. B (1996b). Reflections on the scope of therapeutic jurisprudence. In Law in a therapeutic key. Ed. Wexler, D. B. \& Winick, B. J. Durhamn, North Carolina: Carolina Academic Press.

Wexler, D. B. (2000). Practicing therapeutic jurisprudence: Psychological soft spots and strategies. In D. P. Stolle, D. B. Wexler \& B. J. Winnick (Eds.) Practicing therapeutic jurisprudence; Law as a helping profession, pp. 45 - 67. Durham, NC: Carolina Academic Press.

Williamson, T. M. (1993). From interrogation to investigative interviewing; Strategic trends in police questioning. Journal of Community \& Applied Psychology, Vol. 3, pp. 89 - 99.

Winick, B. J. (2000). Therapeutic jurisprudence and the role of counsel in litigation. In D. P. Stolle, D. B. Wexler \& B. J. Winnick (Eds.) Practicing therapeutic jurisprudence; Law as a helping profession, pp. $309-324$. Durham, NC: Carolina Academic Press.

Wittenbrink, B., Judd, C. \& Park, B. (2001). Spontaneous prejudice in context: Variability in automatically activated attitudes. Journal of Personality and Social Psychology, Vol. 81 (5), pp. 815 -827.

Yuille, J. C., Marxsen, D. \& Cooper, B. (1999). Training investigative interviewing: Adherence to the spirit, as well ass the letter. International Journal of Law and Psychiatry, Vol. 22, 3-4, pp. 323 - 336.

Zimbardo, P. G. (1967). The psychology of police confessions. Psychology Today, 1 (2), pp. $17-20,25-27$. 